Article

\title{
A System-Level Failure Propagation Detectability Using ANFIS for an Aircraft Electrical Power System
}

\author{
Cordelia Mattuvarkuzhali Ezhilarasu *(1) and Ian K Jennions (1) \\ IVHM Centre, Cranfield University, Cranfield, MK43 0AL, UK; i.jennions@cranfield.ac.uk \\ * Correspondence: c.m.ezhilarasu@cranfield.ac.uk
}

Received: 13 March 2020; Accepted: 16 April 2020; Published: 20 April 2020

check for updates

\begin{abstract}
The Electrical Power System (EPS) in an aircraft is designed to interact extensively with other systems. With a growing trend towards more electric aircraft, the complexity of interactions between the EPS and other systems has grown. This has resulted in an increased necessity of implementing health monitoring methods like diagnosis and prognosis of the EPS at the systems level. This paper focuses on developing a diagnostic algorithm for the EPS to detect and isolate faults and their root causes that occur at the Line Replaceable Units (LRUs) connecting with aircraft systems like the engine and the fuel system. This paper aims to achieve this in two steps: (i) developing an EPS digital twin and presenting the simulation results for both healthy and fault scenarios, (ii) developing an Adaptive Neuro-Fuzzy Inference System (ANFIS) monitor to detect faults in the EPS. The results from the ANFIS monitor are processed in two methods: (i) a crisp boundary approach, and (ii) a fuzzy boundary approach. The former approach has a poor misclassification rate; hence the latter method is chosen to combine with causal reasoning for isolating root causes of these interacting faults. The results from both these methods are presented through examples in this paper.
\end{abstract}

Keywords: Electrical Power System; ANFIS; causal reasoning; diagnosis; fault propagation; aircraft; digital twin

\section{Introduction}

The Electrical Power System (EPS) of an aircraft is generally designed to have many interactions with other aircraft systems. For example, the EPS provides electricity required for various valves in the aircraft like the fuel system, the Environmental Control System (ECS), and the pneumatic systems [1]. It is the conduit source of power for the avionics and provides power for all the instruments in the cockpit. The EPS is provided with the required power by the engines and the Auxiliary Power Unit (APU), which in turn generates electricity and provides for the valves and switches in both engines and the APU. The EPS is required for cabin lighting, as well as for the functioning of electrical and electronic appliances like cabin entertainment systems and sensors [2]. With the aircraft industry moving towards low $\mathrm{CO}_{2}$ emissions, clean energy, and light weight, more focus is being given to the concepts of fully electric propulsion systems and all-electric aircraft.

As the dependencies on the EPS grow within an aircraft, more importance is given for detecting and isolating faults in the EPS at an early stage. The effect of any fault in the EPS could easily propagate to other aircraft systems that the EPS interacts with. Some faults in the EPS result in common cause failures, affecting multiple aircraft systems at a given time. Electrical failures in the Boeing 747-4H6 in 2012 [3] and the Airbus A319-111 [4] in 2009 are classic examples of common-mode failures. In the case of the B747-4H6 event in 2012, the root cause of the event was a latent hardware fault on the bus tie breaker whereas, in the A319-111 event in 2009, the incident occurred due to an intermittent fault in the Generator Control Unit which led to the loss of the left electrical network. Both these faults resulted in intermittent blanking of cockpit displays, intermittent loss of power to one of the AC bus bars, 
and resultant degradation of multiple aircraft systems. In the case of B747-4H6, the failure led to the disengagement of all three autopilots and the pilots had to take over the landing manually. In A319-111, the APU generator took over from the failed generator, but many systems, including all means of radio connections, remained inoperative throughout the flight duration. Aircraft incidents like these show the necessity of developing diagnostics for the EPS at the system-level. This would not only detect and isolate the faults that affect the EPS but also prevent the possibility of their propagation to the interacting systems. The diagnosis also helps with the research focusing on health monitoring at the aircraft level, in order to isolate faults propagating to multiple systems [5]. In general, cascading faults result in effects that can be observed in systems other than the point of origin, increasing ambiguity, and resulting in extended downtime and prolonged maintenance as a consequence. Hence diagnostics developed at the systems level, combined with reasoning at the vehicle level, will enable isolation of such faults and their root causes. This will help in reducing the time and money involved in troubleshooting during maintenance [5].

Several research works have been dedicated to developing diagnostic methods for various faults in the aircraft EPS. The Advanced Diagnostic and Prognostic Testbed (ADAPT), an EPS testbed developed by NASA Ames Research Centre, has been used in multiple scenarios to evolve diagnosis and prognosis technologies [6-9]. ADAPT evaluates diagnostic algorithms and software, enables the insertion of faults, and provides a mechanism for evolving the algorithms to be implemented into the vehicles [10]. However, the majority of work found in the EPS diagnostics literature has focused mainly on faults at the components level like wires [11] and relays [8], and the subsystems level like generators [12] and induction motors $[13,14]$. While most researchers work on the performance of the linked systems like the engine and the fuel pump $[1,15,16]$, there is a lack of investigation in isolating the faults from the EPS, which have propagating effects into other aircraft systems.

In this paper, an 'Adaptive Neuro-Fuzzy Inference System (ANFIS) monitor' is developed in MATLAB R2019a to detect the presence of faults in the EPS, within a customizable time period, defined by the user. A hybrid combination of ANFIS monitor with causal reasoning is applied to isolate the root cause of faults found at the Line Replaceable Units (LRUs) connecting the EPS with other aircraft systems. With this objective, in Section 2 of this paper, the digital twin for an aircraft EPS is modeled in MATLAB Simulink R2019a along with its connections to the aircraft engine, the Environmental Control System (ECS), and the fuel system through LRUs as simple as valves and pumps. This is followed by exercising this digital twin under healthy and faulty conditions. Section 3 discusses the steps involved in developing the diagnostic reasoning for EPS using ANFIS and presents the ANFIS monitor that is developed for the detectability of faults in the EPS. Section 4 presents two approaches to processing the results generated by ANFIS: (i) the crisp boundary approach and (ii) the fuzzy boundary approach. These two methods are compared based on their misclassification rate (the ratio of the number of misclassified simulation runs to the total number of simulation runs). Causal reasoning is combined with the better method to isolate the faults and their root causes affecting the aircraft system LRUs. Section 5 provides the conclusion of this paper.

\section{Modeling and Simulation of an Aircraft Electrical Power System (EPS)}

In a typical twin-engine aircraft like a Boeing 737, the EPS is powered by two engine-driven generators. The EPS network generates 3-phase, 115/200 V, $400 \mathrm{~Hz}$ AC power using either the Constant Speed Drive unit, the Variable Speed Constant Frequency unit, or the Integrated Drive Generator to link with the engines. The EPS network is connected to the engine-driven generators through a series of bus arrangements. The two gen buses are powered by either generator, and they supply power to main loads like hydraulic pumps and windows heating. Electricity is then passed on to the main buses, which supply power to the loads like the fuel boost pumps [17]. The alternating current generated is also stepped down to $28 \mathrm{~V}$ AC power for the instrument lighting and converted to $28 \mathrm{~V}$ DC power to provide power to components of other aircraft systems like the engine bleed valves or the fuel system shut-off valves. The standby buses for AC and DC are powered either using the AC transfer bus and 
the DC bus or with batteries via inverters and battery buses, respectively. The AC power sources from the two engine-driven generators do not function in parallel; when an AC power source of a gen bus takes priority, the other existing source is disconnected. The APU driven generator operates identically to the engine-driven generators. It powers the aircraft on ground and serves as a backup for either engine during flight $[17,18]$.

As discussed in the previous paragraph, since only one AC source is active at a given time, this paper considers only the section of the EPS that is powered by one AC source for modeling and the subsequent analysis. To emulate the behavior of an aircraft electrical power system, the EPS digital twin is developed in MATLAB-Simulink R2019asoftware, taking references from some of the existing works [19-21]. More details on the modules used to build the EPS digital twin and the mathematics behind them can be found in these references [22-24].

\subsection{The EPS Digital Twin}

The EPS digital twin consists of a constant speed source from the engine shaft that is fed to a generator of $40 \mathrm{kVA}$ capacity. This generator is defined by a simplified synchronous machine in MATLAB Simulink, which produces $115 / 200 \mathrm{~V}$ AC power at $400 \mathrm{~Hz}$. For the given frequency f, the synchronous speed $\mathrm{N}_{\mathrm{s}}$ at which the required voltage is produced by the synchronous machine is calculated using the following formula:

$$
\mathrm{N}_{\mathrm{s}}=\mathrm{f}(2 / \mathrm{P}) \times 60=400 \mathrm{~Hz} \times(120 / 4)=12,000 \mathrm{rpm}
$$

where $\mathrm{P}$ is the number of poles in the generator. With this result, all the simulations of the EPS digital twin will be run at a constant speed of 12,000 rpm [18]. The synchronized machine also takes regulated field voltage as an input, which is fed from the IEEE type 1 voltage regulator combined excitation system. Considering the dissipation losses in the circuit, the total apparent power generated by this synchronous machine is calculated using the following formula [21]:

$$
\text { Apparent Power, } p=3 \mathrm{~V}_{\text {rms }} \mathrm{I}_{\mathrm{rms}}(\mathrm{kVA})
$$

where $\mathrm{rms}=$ root mean square.

As mentioned in Section 1, with the growing demand for more electrification of advanced aircraft, the EPS is designed to distribute power to several aircraft systems through its constituent LRUs. For this EPS digital twin, the following LRUs in the aircraft systems are considered for this simulation, with the necessary parameters taken from their respective technical specification sheets provided by their commercial suppliers [25-28]. Figure 1 shows the defined MATLAB Simulink model developed for the EPS representative discussed in this paper.

The 115/200 V AC power is provided to the fuel pump AC induction motor. The induction motor is defined by an asynchronous machine rated at $9 \mathrm{KW}$ power and $8000 \mathrm{rpm}$, with a squirrel cage rotor that results in the rotor speed required to run the fuel pump. The paper refers to the power distributed to this LRU as Power_FSPump; the motor's speed, torque, and stator current are referred to as FS_Motor_Speed, FS_Motor_Torque, and FS_Motor_Stator_I, respectively.

The AC power is distributed to the Transformer Rectifier Unit (Power_TRU) and is converted to $28 \mathrm{~V}$ DC. This DC power is then supplied to a valve and a nozzle in the fuel system, to a bleed air system high-pressure shut-off valve in the engine, and a temperature control valve in the ECS. This paper refers to these LRUs as FS_Valve, FS_Nozzle, Eng_BleedValve, and ECS_TCValve, respectively. 


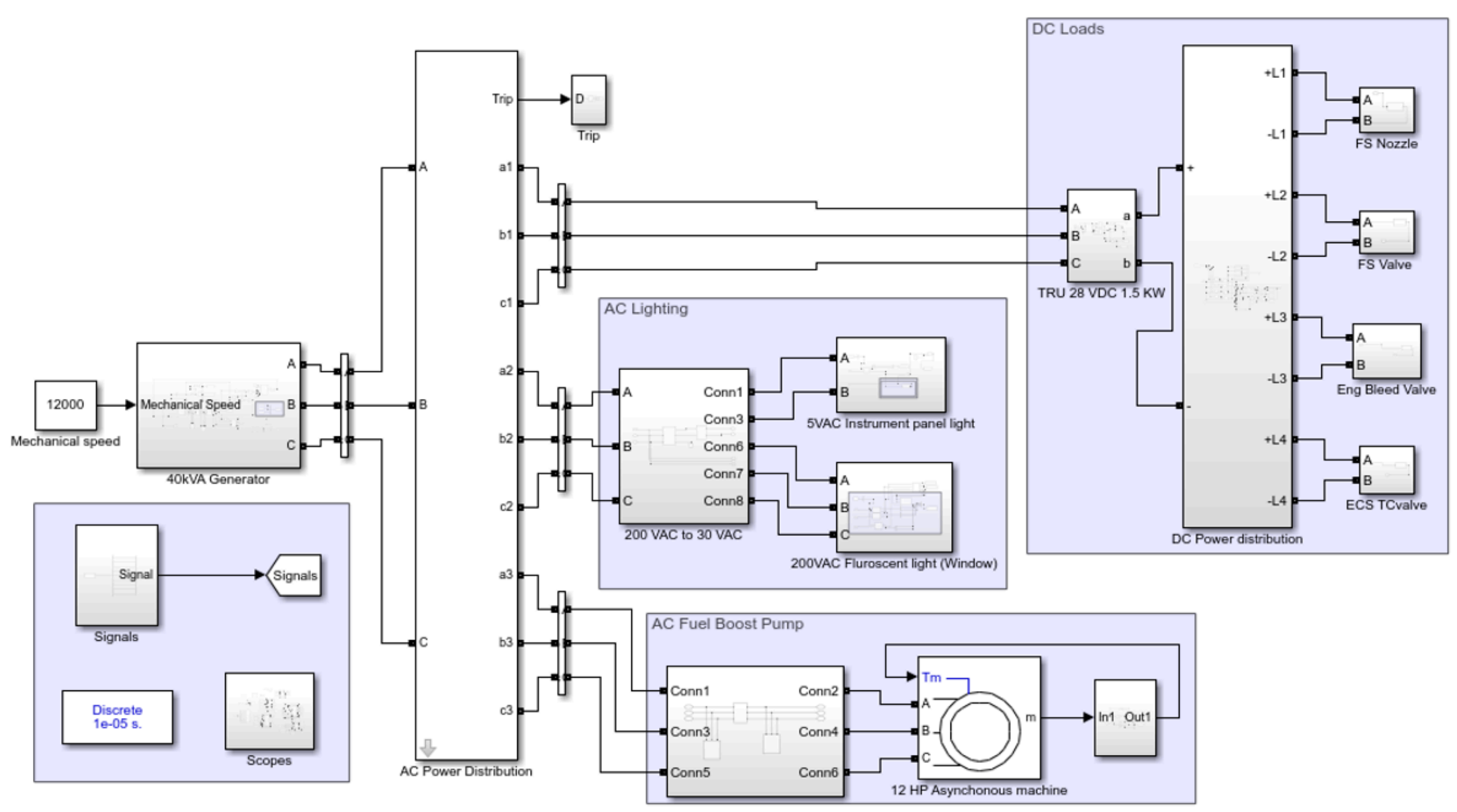

Figure 1. MATLAB-Simulink model for the aircraft Electrical Power System (EPS). 
The AC power distributed to the AC Lamps (Power_ACLamp) is directly provided for the cabin window fluorescent lights (AC_Fluro) and stepped down to $5 \mathrm{~V}$ AC for the cockpit instrument panel lights (AC_Instru).

The AC power generated is referred to as Power_ACLoad and is distributed at each node representing the aircraft systems, and is also calculated using Equation (2). Random noise is added in the measurement devices, in order to avoid replicating an ideal condition for the EPS.

Table 1 presents the performance of the EPS digital twin at a constant speed of 12,000 rpm, considering a steady state as the operating condition. This simulated condition is considered as the healthy state condition or the baseline for the EPS digital twin. Following the simulation with the healthy scenario, the next section discusses the faults induced in the EPS digital twin.

Table 1. Measured values during the Healthy Run.

\begin{tabular}{ccc}
\hline Monitored Parameters & Healthy Measurements & Unit \\
\hline Power_ACLoad & 4182.908 & VA \\
Power_FSPump & 4001.362 & VA \\
Power_ACLamp & 73.349 & VA \\
Power_TRU & 111.102 & VA \\
FS_Motor_Speed & 311.813 & rad/sec \\
FS_Motor_Stator_I & 4.822 & $\mathrm{~A}$ \\
FS_Motor_Torque & 5.612 & $\mathrm{Nm}$ \\
FS_Nozzle_I & 0.908 & $\mathrm{~A}$ \\
FS_Valve_I & 0.889 & $\mathrm{~A}$ \\
Eng_BleedValve_I & 0.901 & $\mathrm{~A}$ \\
ECS_TCValve_I & 0.890 & $\mathrm{~A}$ \\
AC_Fluro_I & 0.259 & $\mathrm{~A}$ \\
AC_Instru_I & 4.892 & $\mathrm{~A}$ \\
\hline
\end{tabular}

\subsection{Fault Injection in the EPS Digital Twin}

The EPS supplies power to required LRUs of the aircraft systems through a series of switches and circuit breakers that protect the electrical circuits from events like overcurrent surge. These circuit breakers are modeled to trip on their own when the current exceeds the defined limit, as shown in Figure 2a. These circuit breakers can also be tripped at the beginning of the simulation, on purpose, by providing a fault signal as input to these components. In Figure 2b, DC_TRU_B, AC_Lamp_B, and FS_ACMotor_B are the fault input signals that would induce circuit breaker tripping in the distribution node that supplies AC Power to TRU, AC lamps, and FS motor, respectively. Injecting faults in the circuit breakers will stop the current flow to the respective node that supplies power to the LRU connecting to a particular aircraft system like the engine, the fuel system, or the ECS.

Similarly, faults can be injected via the integrated gate bipolar transistor (IGBT) switches that connect to the valves and nozzles within the DC circuit (as seen in Figure 3), as well as through the switches in AC lamp circuits (not shown in the figure). The faults in the DC circuits from Figure 3 emulate the stuck open scenarios by opening the IGBT switches to a partial degree. For testing purposes, FS_valve switch is stuck at $80 \%$, FS_Nozzle switch is stuck at 70\%, Eng_BleedValve is stuck at $60 \%$, and the ECS_TCValve is stuck at $50 \%$. Figure 3 also shows the noise signals added to voltage measurements. Similar noise is added to voltage measurements in AC lamp circuits. 


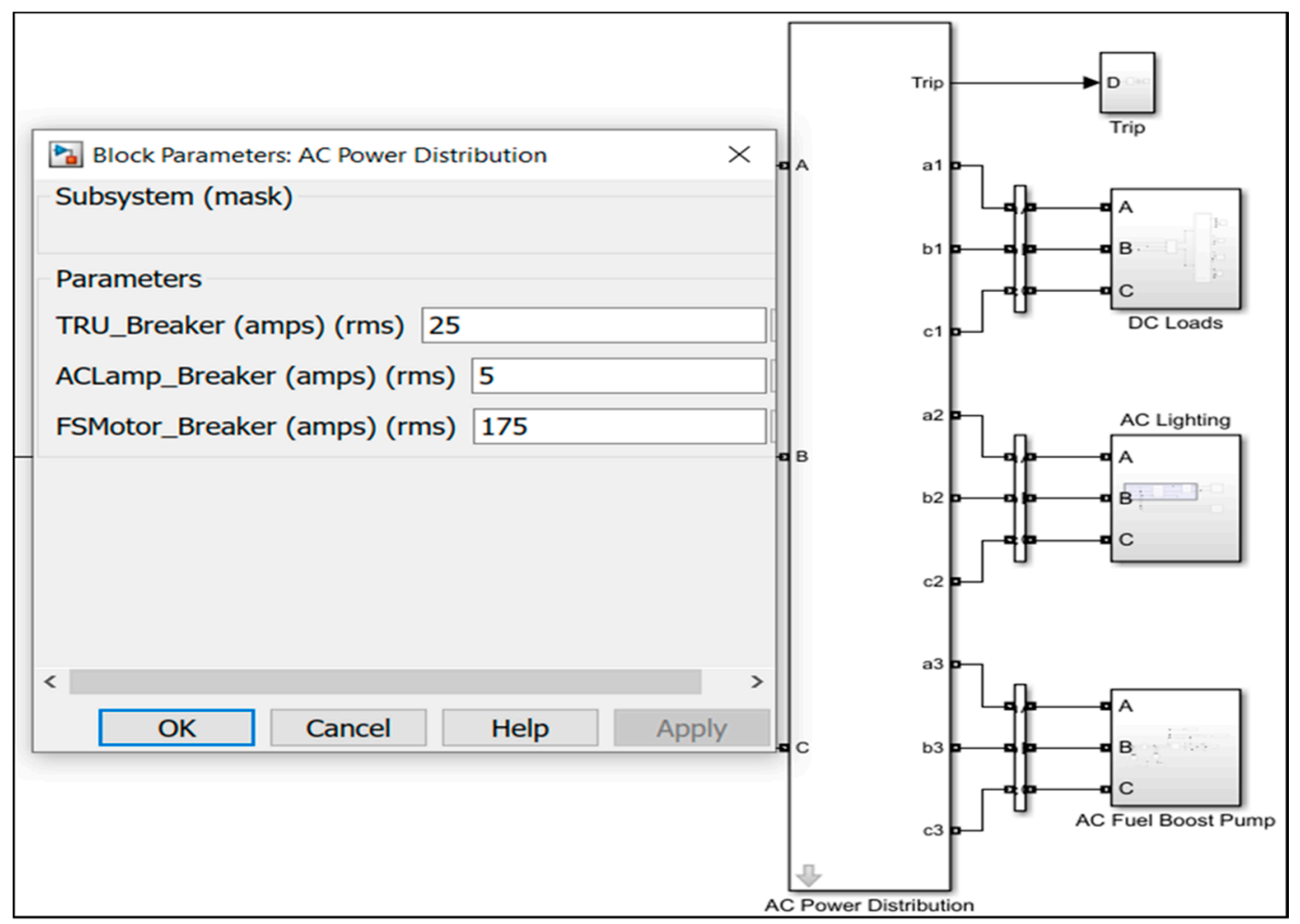

(a)

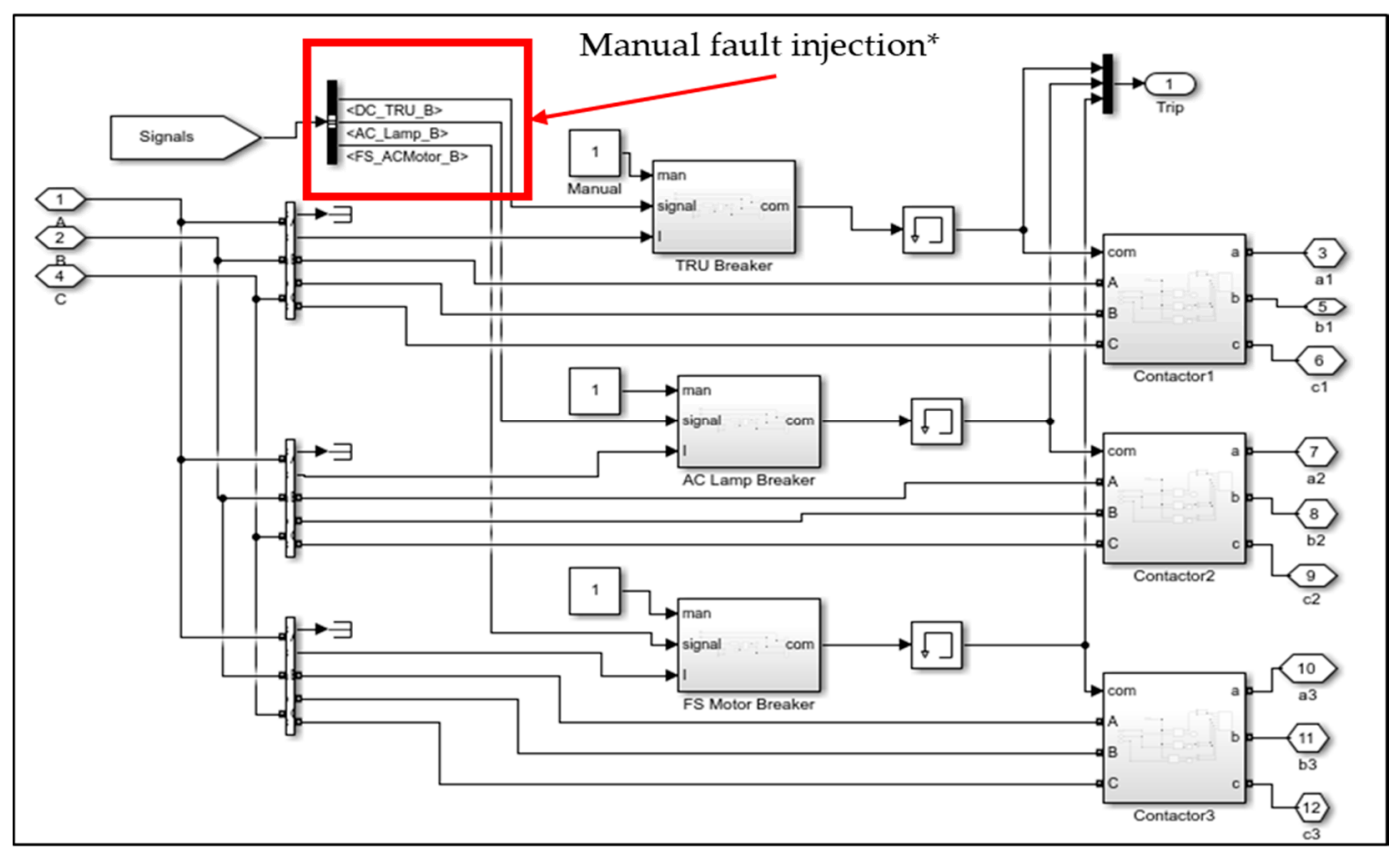

(b)

Figure 2. Fault injection in circuit breakers connecting generators to other aircraft systems: (a) User input current limits set for circuit breakers; (b) Manual tripping input inside the AC power distribution mask. 


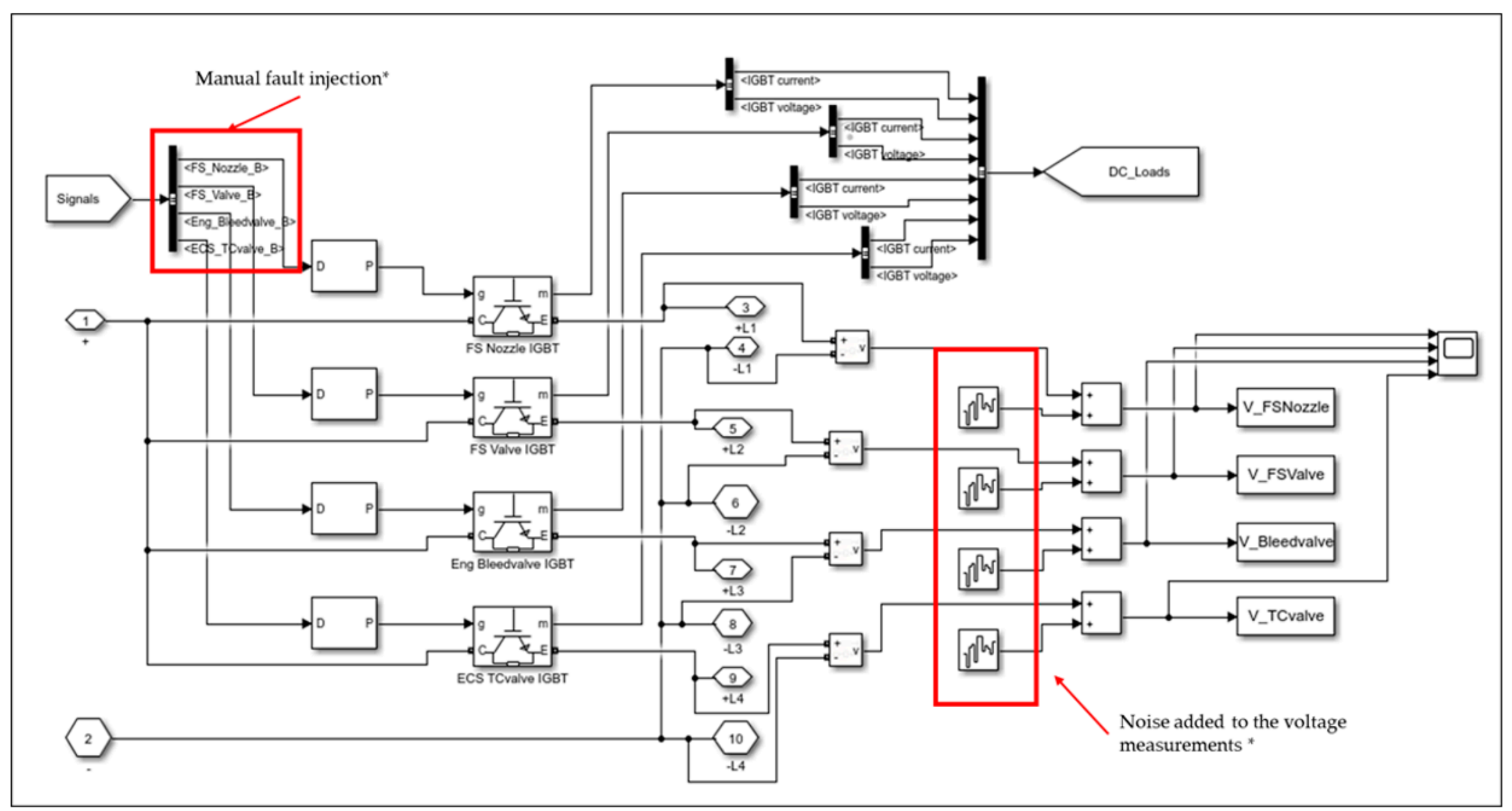

Figure 3. Fault injection to DC loads via integrated gate bipolar transistor (IGBT) switches and noise signal added to voltage measurements. 
In the case of the FSPump AC induction motor, there are several methods to inject faults that would result in the reduction of its rotor speed output. For this paper, the variation of the supply voltage method is chosen [29]. This is carried out by inserting a step-down transformer in the motor circuit, as shown in Figure 4. Through this, the supply voltage to the pump motor is reduced to induce the fault.

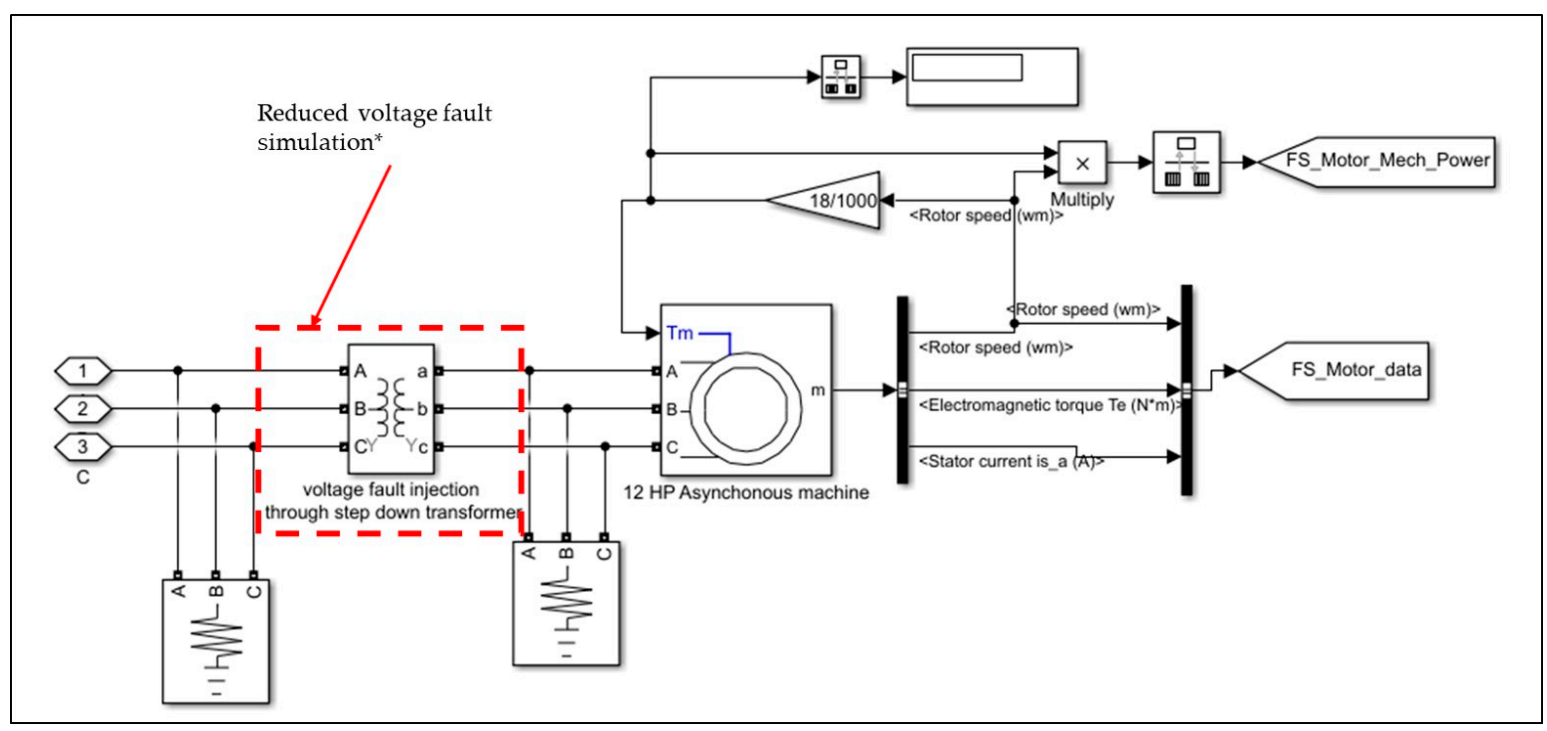

Figure 4. Fault injection in AC pump motor by reduced voltage supply (F10).

Considering only abrupt faults, as either intermittent or constant over time, faults chosen for diagnosis in the EPS digital twin are listed in Table 2. As discussed above, the faults are chosen in such a way that, when injected, their effects can be observed in the overall power generated by the generator and the overall power consumed by their corresponding LRUs. These faults are also the most common electrical faults explored in the aircraft industry. For demonstration purposes and to avoid a lengthier presentation, all faults listed in Table 2 (F1, F2, . , F9) are injected for a duration of $0.25 \mathrm{~s}$ each, instead of injecting individual faults per simulation run. Fault F10 is simulated separately.

The effects of the faults on the systems and their components and how they affect other systems are observed and compared with the healthy case simulation from Table 1. The faults either affect the power supply to the entire system along with their subsystems or only the LRUs based on the location of the fault injection. This can be observed in Figure 5 (the fault ids are mentioned in the red box, near their respective effects in the plots). For example, when the fault F5 is injected (circuit breaker connecting the power distribution node to TRU is tripped) at $\mathrm{t}=2.5 \mathrm{~s}$ to $\mathrm{t}=2.75 \mathrm{~s}$ as per Table 2, the fault cuts off the current supply to all the valves and nozzles in the DC circuit (Figure 5 middle column at $\mathrm{t}=2.5 \mathrm{~s}$ to $\mathrm{t}=2.75 \mathrm{~s}$ ). However, when the faults F1, F2, F3, and F4 (scenarios of switch stuck open at the LRUs), are injected at their respective simulation times from Table 2, they affect the current consumed by the concerned LRU only. This can be observed from the left column second plot (Power_TRU) and the entire middle column of Figure 5. Likewise, when the fault F7 (circuit breaker tripped at the distribution node connecting the AC lamps) is injected at $t=3.5 \mathrm{~s}$ to $t=3.75$ $\mathrm{s}$ as per Table 2, the current is reduced to both the AC instrument panel lamp and at the AC cabin window fluorescent lamp (can be observed in right column bottom two plots of Figure 5). However, the faults F8 and F9 (scenarios of switch stuck open at the LRUs) injected at the simulation times listed in Table 2, affect the current consumed by the respective LRUs only. These cases can be observed in the left column bottom plot (Power_ACLamp) and right column bottom two plots of Figure 5. In the case of faults in the AC motor, when the circuit breaker is tripped at the AC power distribution node (Fault $\mathrm{F} 6$ at $\mathrm{t}=3.0 \mathrm{~s}$ to $\mathrm{t}=3.25 \mathrm{~s}$ ), the motor does not receive any power, and hence there is no speed and current (left column third plot (Power_FSPump) and right column top two plots of Figure 5). It is to be 
noted that, in the top plot on the left column of Figure 5 (Power_total), only the effect of fault F6 is observed. This is due to the difference in magnitude of power consumed by Power_FSPump when compared to the Power_TRU and Power_ACLamp. In the case of fault F10, when the supply voltage is reduced, the rotor speed is lower than the nominal speed that is observed during the healthy case simulation. The reduced supply voltage scenario is shown in Figure 6. Thus, all the faults listed in Table 2 affect the overall power output from the simulation of EPS digital twin, along with the power consumption of the aircraft systems the EPS is connected to.

Table 2. Faults injected in the EPS Digital Twin.

\begin{tabular}{|c|c|c|c|c|}
\hline Fault_Id & Type of Fault & Location & Fault Label & $\begin{array}{l}\text { Timeline of Fault } \\
\text { Injection }\end{array}$ \\
\hline $\mathrm{F} 1$ & $\begin{array}{c}\text { Switch stuck open } \\
@ 80 \%\end{array}$ & $\begin{array}{l}\text { DC supply to fuel system } \\
\text { nozzle }\end{array}$ & FS_Nozzle_SwitchStuckopen & $\mathrm{t}=0.25 \mathrm{~s}$ to $\mathrm{t}=0.5 \mathrm{~s}$ \\
\hline F2 & $\begin{array}{c}\text { Switch stuck open } \\
\qquad 70 \%\end{array}$ & $\begin{array}{l}\text { DC supply to fuel system } \\
\text { shut-off valve }\end{array}$ & FS_Valve_SwitchStuckopen & $\mathrm{t}=0.75 \mathrm{~s}$ to $\mathrm{t}=1.0 \mathrm{~s}$ \\
\hline F3 & $\begin{array}{c}\text { Switch stuck open } \\
\qquad 60 \%\end{array}$ & $\begin{array}{c}\text { DC supply to engine bleed } \\
\text { valve }\end{array}$ & Eng_BleedValve_SwitchStuckopen & $\mathrm{t}=1.25 \mathrm{~s}$ to $\mathrm{t}=1.5 \mathrm{~s}$ \\
\hline F4 & $\begin{array}{c}\text { Switch stuck open } \\
@ 50 \%\end{array}$ & $\begin{array}{l}\text { DC supply to ECS } \\
\text { Temperature control valve }\end{array}$ & ECS_TCValve_SwitchStuckopen & $\mathrm{t}=1.75 \mathrm{~s}$ to $\mathrm{t}=2.0 \mathrm{~s}$ \\
\hline F5 & Circuit breaker trip & $\begin{array}{l}\text { AC power distribution node } \\
\text { to TRU for DC circuits }\end{array}$ & DC_TRU_B & $\mathrm{t}=2.5 \mathrm{~s}$ to $\mathrm{t}=2.75 \mathrm{~s}$ \\
\hline F6 & Circuit breaker trip & $\begin{array}{l}\text { AC power distribution node } \\
\text { to AC fuel pump motor }\end{array}$ & FS_ACMotor_B & $\mathrm{t}=3.0 \mathrm{~s}$ to $\mathrm{t}=3.25 \mathrm{~s}$ \\
\hline F7 & Circuit breaker trip & $\begin{array}{l}\text { AC power distribution node } \\
\text { to AC Lamps }\end{array}$ & AC_Lamp_B & $\mathrm{t}=3.5 \mathrm{~s}$ to $\mathrm{t}=3.75 \mathrm{~s}$ \\
\hline F8 & Switch stuck open & $\begin{array}{l}\text { AC supply to Instrument } \\
\text { panel lamp }\end{array}$ & AC_Instru_Switchopen & $\mathrm{t}=4.0 \mathrm{~s}$ to $\mathrm{t}=4.25 \mathrm{~s}$ \\
\hline F9 & Switch stuck open & $\begin{array}{l}\text { AC supply to cabin window } \\
\text { fluorescent light }\end{array}$ & AC_fluro_Switchopen & $\mathrm{t}=4.5 \mathrm{~s}$ to $\mathrm{t}=4.75 \mathrm{~s}$ \\
\hline F10 & Voltage reduction & $\begin{array}{l}\text { Line supply voltage to AC fuel } \\
\text { pump motor }\end{array}$ & FS_Motor_lowvoltage & $\begin{array}{l}\text { Simulated } \\
\text { separately }\end{array}$ \\
\hline
\end{tabular}
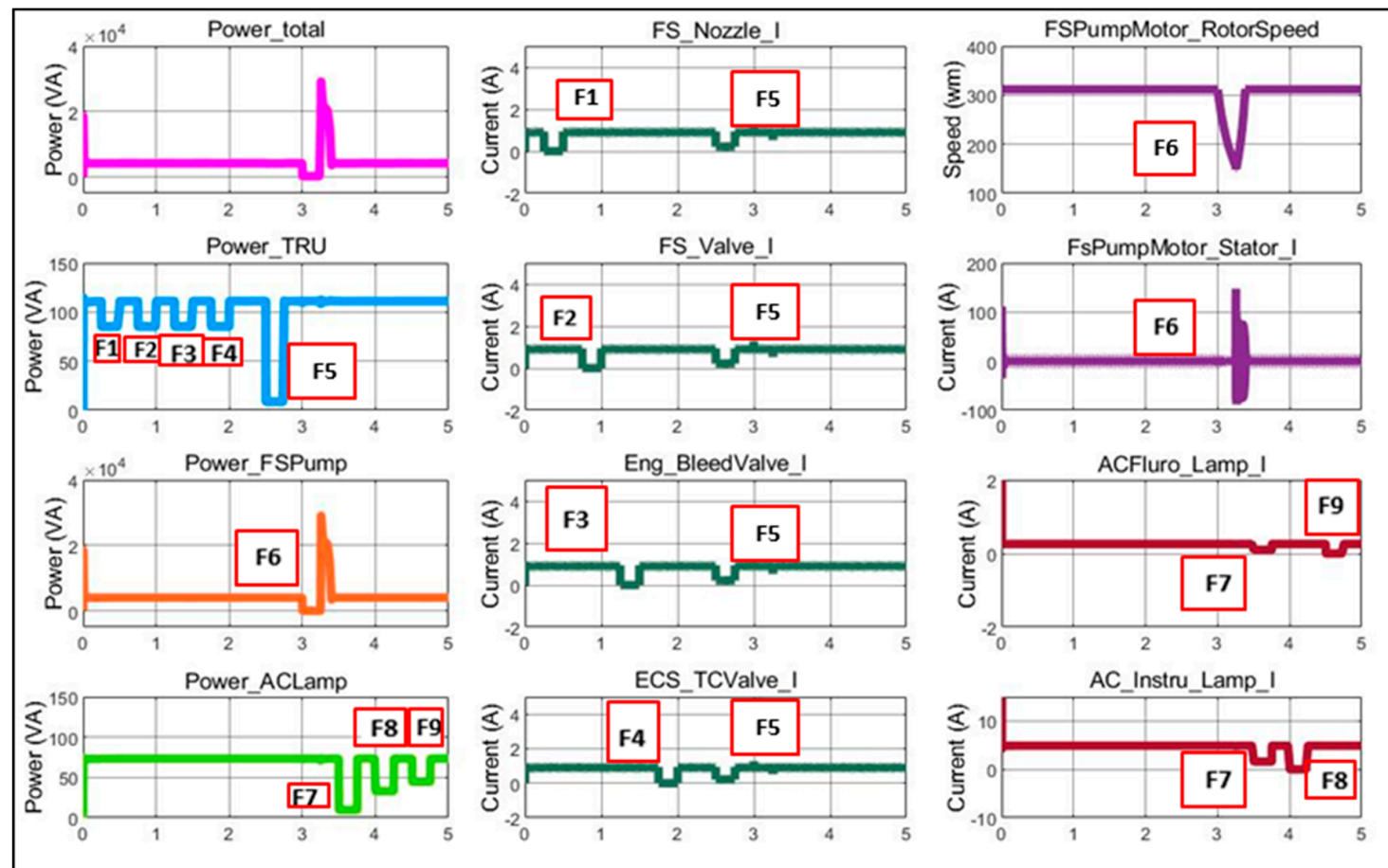

Figure 5. EPS performance during various fault scenarios (faults F1, F2, .. , F9). Left column: Total power generated and power consumed by DC TRU, FS Pump, and AC Lamp (kVA). Middle column: Currents at DC Loads. Right column, top two plots: FS Pump characteristics. Right column, bottom two plots: Currents at AC Lamps. 


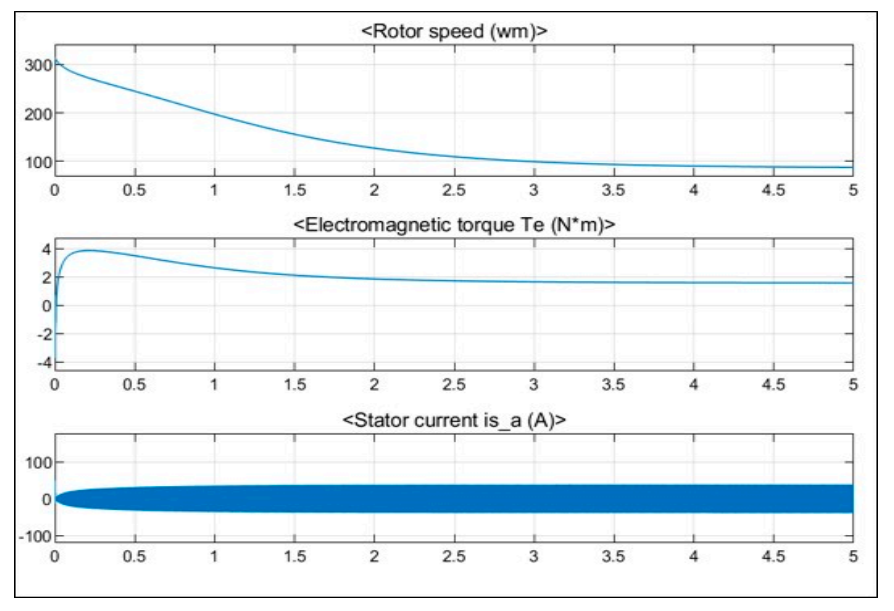

Figure 6. Pump motor characteristics for reduced voltage (F10).

\section{Diagnostic Reasoning for the EPS}

The simulations run for both healthy and faulty conditions in the EPS digital twin show that faults induced in the EPS affect the LRUs of other systems, thus propagating their effects to these interacting systems. In order to detect and isolate the faults propagating to other aircraft systems from the EPS, a diagnostic reasoning engine is developed through a series of steps, as discussed below.

Data is collected by running the simulation at both healthy and all known fault scenarios. A set of parameters was chosen to monitor the health of the EPS digital twin during these simulations, and the raw data was collected for these parameters through sampling.

Preprocessing of the sampled raw data is undertaken by calculating the root mean square (rms) values of the monitored parameters followed by computing the mean values of the steady-state data.

Factor analysis is carried out using the computed mean values to understand the effects of injected faults on the monitored parameters. This step helps in shortlisting the factors that need to be considered for building the diagnostic reasoning engine and ignoring the redundant parameters.

Thresholds are determined to define the diagnostic rules for the reasoning engine. If crisp thresholds are established between the parameters for all the simulated scenarios, these threshold values can be used to define the diagnostic rules for the reasoning engine. However, from Figure 5, it is observed that for certain faults like F7 or F1, the apparent power does not vary much from the $100 \%$ healthy case results. In such scenarios, defining a crisp boundary of the parameter in order to differentiate a healthy case from the fault cases and to differentiate a fault case from another, would require a large number of very specific rules. To avoid this, the thresholds will hence be defined by fuzzy boundaries, and diagnostic rules will be framed using fuzzy reasoning.

This step involves developing fuzzy diagnostic reasoning. In order to avoid specificity in the threshold values, the membership functions of the fuzzy system are determined using artificial neural networks. The following subsections present the fundamentals of ANFIS and how it is implemented for the EPS diagnostics.

\subsection{Brief Description of ANFIS}

The Adaptive Neuro-Fuzzy Inference System (ANFIS) is the combination of artificial neural networks (ANN) with Takagi-Sugeno fuzzy reasoning [30]. A general fuzzy inference system (FIS) operates by the following steps:

1. Input parameters are fuzzified by defining membership functions,

2. Logical operators like AND, OR, and NOT are applied to combine the membership functions of the input parameters to get a set of 'if-then' rules along with their weights, 
3. The consequent parts of the rules are implemented depending upon their firing strengths (weights), and

4. The outputs are calculated, aggregated, and de-fuzzified to provide the final output.

A generalized example to demonstrate the above-mentioned steps is shown in Figure 7. Consider a first-order Sugeno FIS for given two-parameter inputs A and B presented in the following sets of equations [30], as seen in Figure 7a.

Rule 1: If $\mathrm{A}$ is $\mathrm{X} 1$ and $\mathrm{B}$ is $\mathrm{Y} 1$,

$$
\text { then } \mathrm{z} 1=\mathrm{p} 1 \times \mathrm{A}+\mathrm{q} 1 \times \mathrm{B}+\mathrm{r} 1
$$

Rule 2: If $\mathrm{A}$ is $\mathrm{X} 2$ and $\mathrm{B}$ is $\mathrm{Y} 2$,

$$
\text { then } \mathrm{z} 2=\mathrm{p} 2 \times \mathrm{A}+\mathrm{q} 2 \times \mathrm{B}+\mathrm{r} 2
$$

where $\mathrm{p} 1, \mathrm{p} 2, \mathrm{q} 1, \mathrm{q} 2, \mathrm{r} 1$, and $\mathrm{r} 2$ are linear parameters, and $\mathrm{X} 1, \mathrm{X} 2, \mathrm{Y} 1$, and $\mathrm{Y} 2$ are non-linear parameters. The inputs of $A$ and $B$ are fuzzified by assigning membership functions, say $\mu$ and $v$. These membership functions represent the degree to which A and B satisfy pertaining to their fuzzy labels X1, Y1, X2, and Y2. Logical operator AND is applied to establish the relationship between the A and B using their membership functions. For example, consider the weights that could be calculated by the following equations:

$$
\begin{aligned}
& \mathrm{w} 1=\operatorname{AND}\left(\mu \mathrm{X}_{1}(\mathrm{~A}), \nu \mathrm{Y}_{1}(\mathrm{~B})\right) \\
& \mathrm{w} 2=\operatorname{AND}\left(\mu \mathrm{X}_{2}(\mathrm{~A}), \nu \mathrm{Y}_{2}(\mathrm{~B})\right)
\end{aligned}
$$
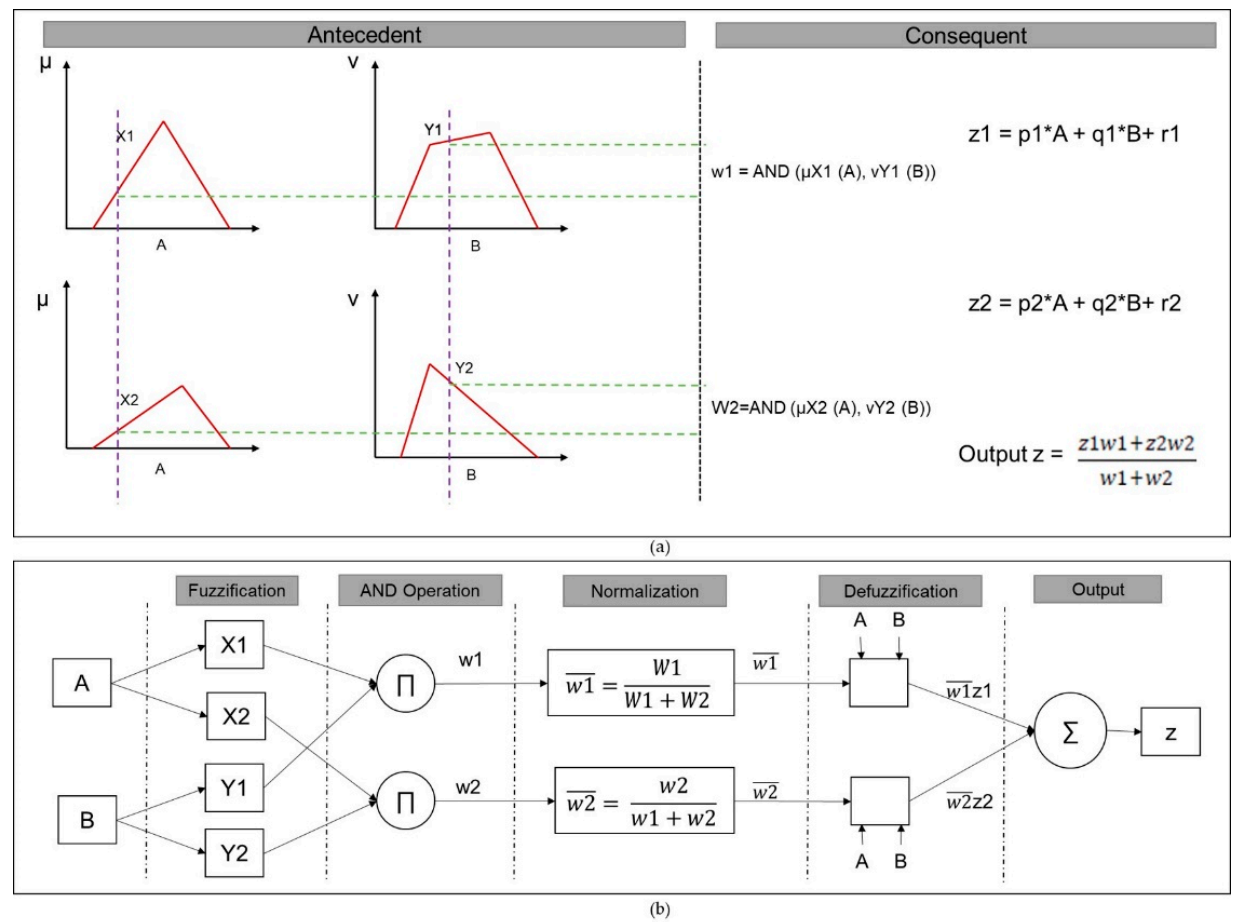

Figure 7. (a) First order Takagi-Sugeno fuzzy reasoning (b) Adaptive Neuro-Fuzzy Inference System (ANFIS) structure (adapted from [30]).

Once the weights of the fired rules, $\mathrm{w} 1$ and $\mathrm{w} 2$, are computed, they are combined with the outputs $\mathrm{z} 1$ and $\mathrm{z} 2$. The total output ' $z$ ' is given by calculating the weighted average of the outputs, as given in Equation (7) [30]. While A and B are fuzzy sets in the antecedent, ' $z$ ' is a crisp function in the consequent side.

$$
\text { Output } z=(\mathrm{z} 1 \times \mathrm{w} 1+\mathrm{z} 2 \times \mathrm{w} 2) /(\mathrm{w} 1+\mathrm{w} 2)
$$


The ANN is used to tune the membership functions in the Takagi-Sugeno FIS, in order to optimize the relationship between the input parameters and their respective fuzzy labels, resulting in the algorithm, ANFIS (as seen in Figure 7b). The neural network in ANFIS estimates errors and adjusts the membership function parameters to reduce the errors. The parameters are estimated either by using backpropagation or by a hybrid method that combines least squares estimation with backpropagation.

\subsection{An ANFIS Monitor for the EPS}

To detect and isolate faults in the EPS, an ANFIS function is developed using the Neuro-Fuzzy designer toolbox in MATLAB R2019a [31,32]. Using all the monitored parameters to develop ANFIS is impractical, as it consumes a lot of memory and ends up developing redundant rules. For example, from Figure 1, it is seen that power can be calculated and monitored from 11 nodes (one node from the generator, three nodes distributing power, and power supplied to four DC nodes, two AC lamp nodes, and one AC pump node). Considering these 11 nodes, and AC motor rotor speed as the 12th monitored parameter, if every parameter is defined with three membership functions, the number of rules developed to map the relationship between the membership functions will be:

$$
\text { No. of rules }=(12 \times 3)^{2}=1296
$$

In reality, the EPS interacts with many aircraft systems through the LRUs. Monitoring power distributed at all these nodes will not be efficient for the diagnostic process as it will consume a lot of memory and time, and the simulation might not even converge in certain scenarios. Hence instead of using all monitored parameters, only a few should be selected for further analysis to detect the presence of a fault in the EPS. In this paper, the Power_Generated parameter is chosen for the purpose of diagnosis. This is due to the observation made from Table 1, where the total power generated in row 1 is almost equal to the total power consumed in rows $2-4$, the slight difference accounting for the losses and the noise measurements. This eliminates the need to monitor both the power distributing and consuming nodes. Any presence of fault could ideally be detected by monitoring only the power generated from the EPS. A Gaussian membership function with three categories (low, medium, high) is defined for the monitored parameter, Power_Generated, using the Neuro-Fuzzy designer toolbox. Hence, the number of rules generated in this case becomes three. The ANFIS function is implemented as a monitor that screens the parameter Power_Generated, for a defined window of time. This defined time period is programmed to be any number of windows according to the user's interest, thus making the ANFIS monitor customizable.

\section{Results and Discussion}

Simulations are run for healthy and various faulty scenarios and the processed steady-state data from Power_Generated. The total data processed for analysis is split into training ( $40 \%$ of the data) and testing ( $60 \%$ of the data). In general, ANFIS generates the output ' $z$ ' in numbers between $0-5$ with decimal points ( 0 being the lowest power generated and 5 being the highest). These values of ' $z$ ' are processed in two different methods for further isolation of faults.

\subsection{Method 1: The Crisp Boundary Approach}

The output values, ' $z$ ' with decimals generated by ANFIS, are rounded up to discrete ranks, providing crisp boundaries between the regions. This results in six discrete values; thus, six distinct regions, from Region 5 to Region 0, as shown in Figure 8. Any surge in power generated, due to an unsteady state is classified as 'undefined'. ANFIS is trained with the training data, and its ability to estimate the output based on the power generated is evaluated using the testing data, where it produced a root mean square error of 0.31 .

The trained ANFIS function is programmed to detect any presence of faults in the EPS after every simulation run. For demonstration purposes, the ANFIS monitor screens the steady-state simulation 
run time every $0.25 \mathrm{~s}$ to check the state of total power generated by the EPS and in this paper, two cases are tested.

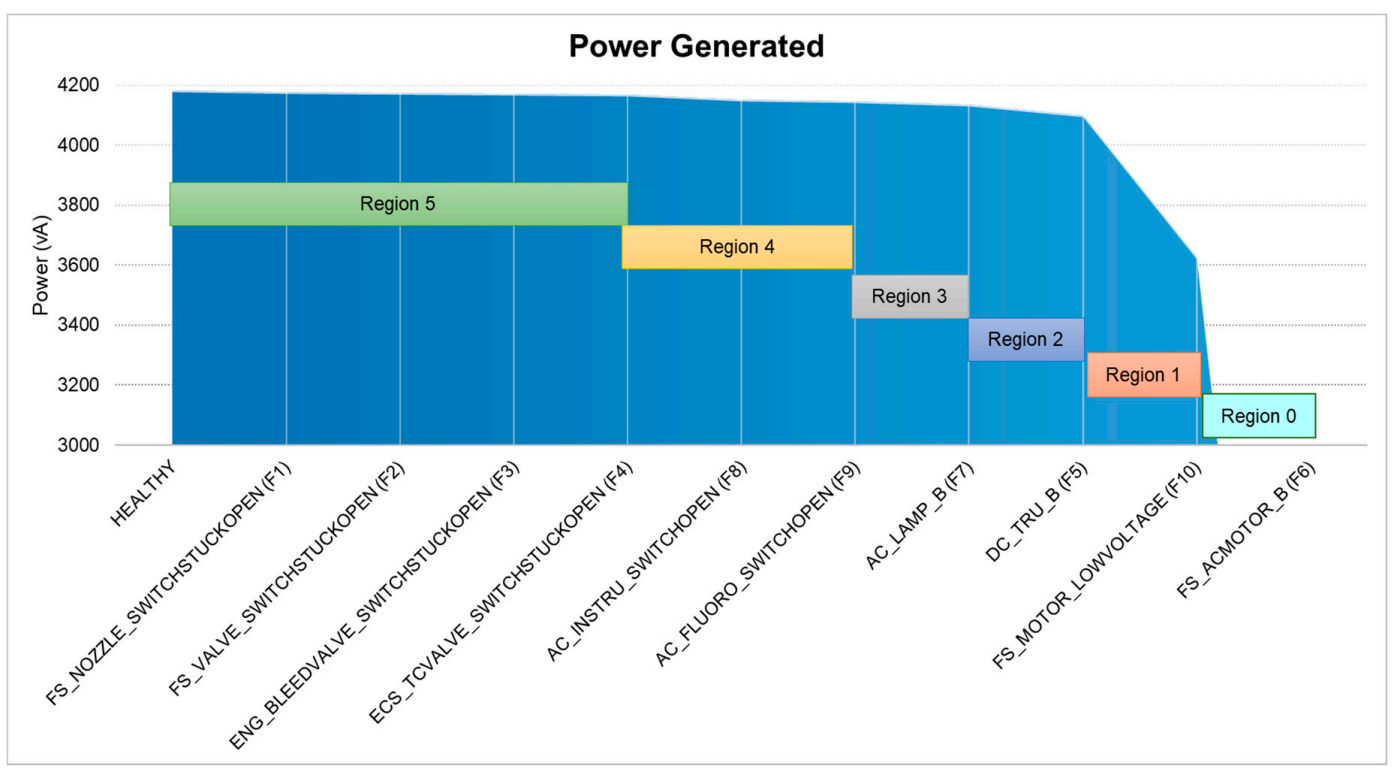

Figure 8. Healthy and faulty scenarios classified based on apparent power generated using the crisp boundary approach.

\subsubsection{Healthy Case}

When the EPS is run for a healthy scenario (Figure 9a), the result generated by the ANFIS monitor is as shown in Figure 9b. The ANFIS monitor checks the simulation run every $0.25 \mathrm{~s}$, and the results show 'Region $5^{\prime}$ for every time window.

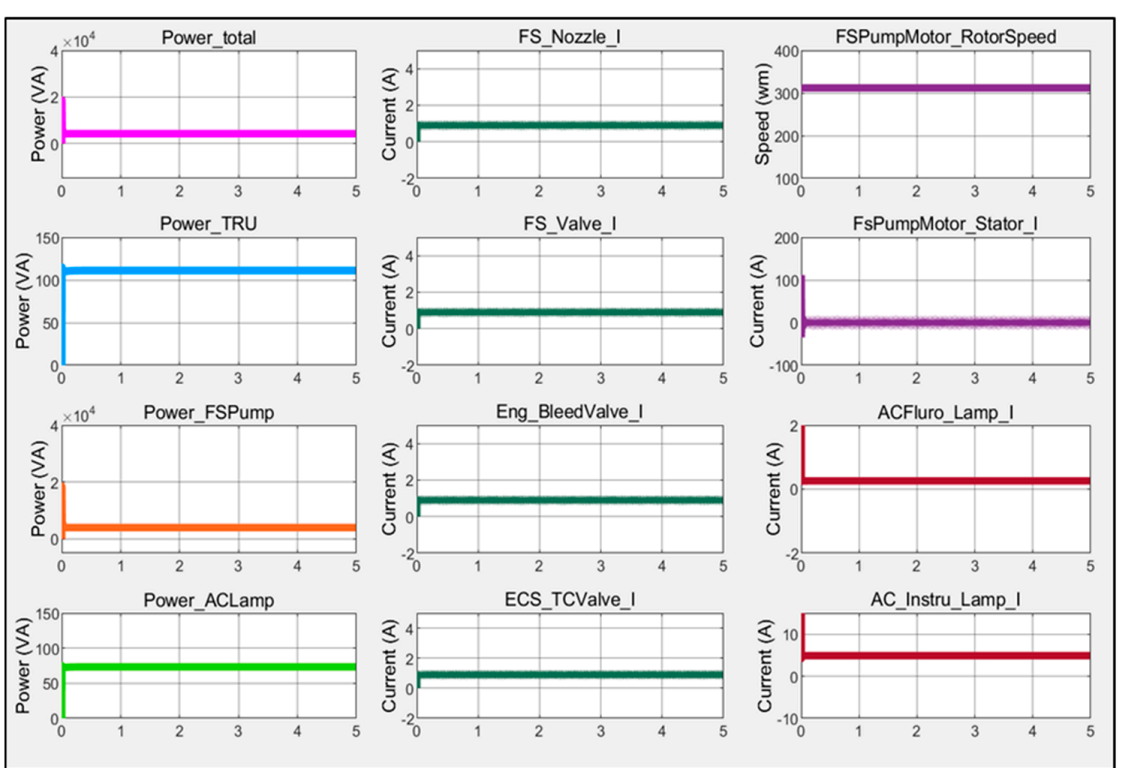

(a)

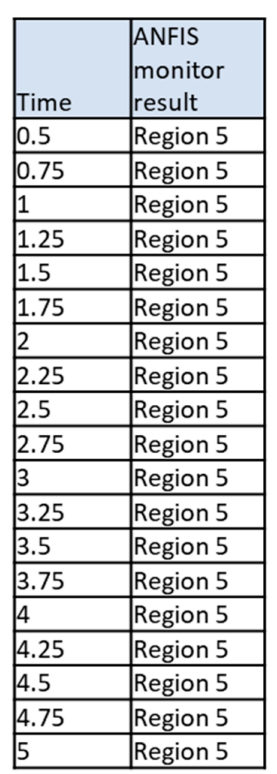

(b)

Figure 9. Healthy scenario using the crisp boundary approach. (a) EPS performance in terms of apparent power (left column), DC currents (middle column), [ump performance (top two plots in the right column), AC lamps current (bottom two plots in the right column). (b) The corresponding results generated by ANFIS monitor using Method 1 approach. 


\subsubsection{Faulty Case}

In an ideal testing scenario, only a single fault scenario is tested. However, for the purposes of demonstration, the same faults from Table 2 (for $0.25 \mathrm{~s}$ each) are tested in this case. It can be observed in Figure $10 \mathrm{~b}$ that the ANFIS monitor has not classified the regions correctly. For example, fault F7 $(\mathrm{t}=3.5 \mathrm{~s}$ to $\mathrm{t}=3.75 \mathrm{~s})$ is classified as 'Region $4^{\prime}$ at $\mathrm{t}=3.75 \mathrm{~s}$ instead of 'Region $3^{\prime}$ and fault F5 $(\mathrm{t}=2.5 \mathrm{~s}$ to $\mathrm{t}=2.75 \mathrm{~s}$ ) is classified as 'Region $3^{\prime}$ at $\mathrm{t}=2.75 \mathrm{~s}$ instead of 'Region $2^{\prime}$, as assigned in Figure $10 \mathrm{~b}$.
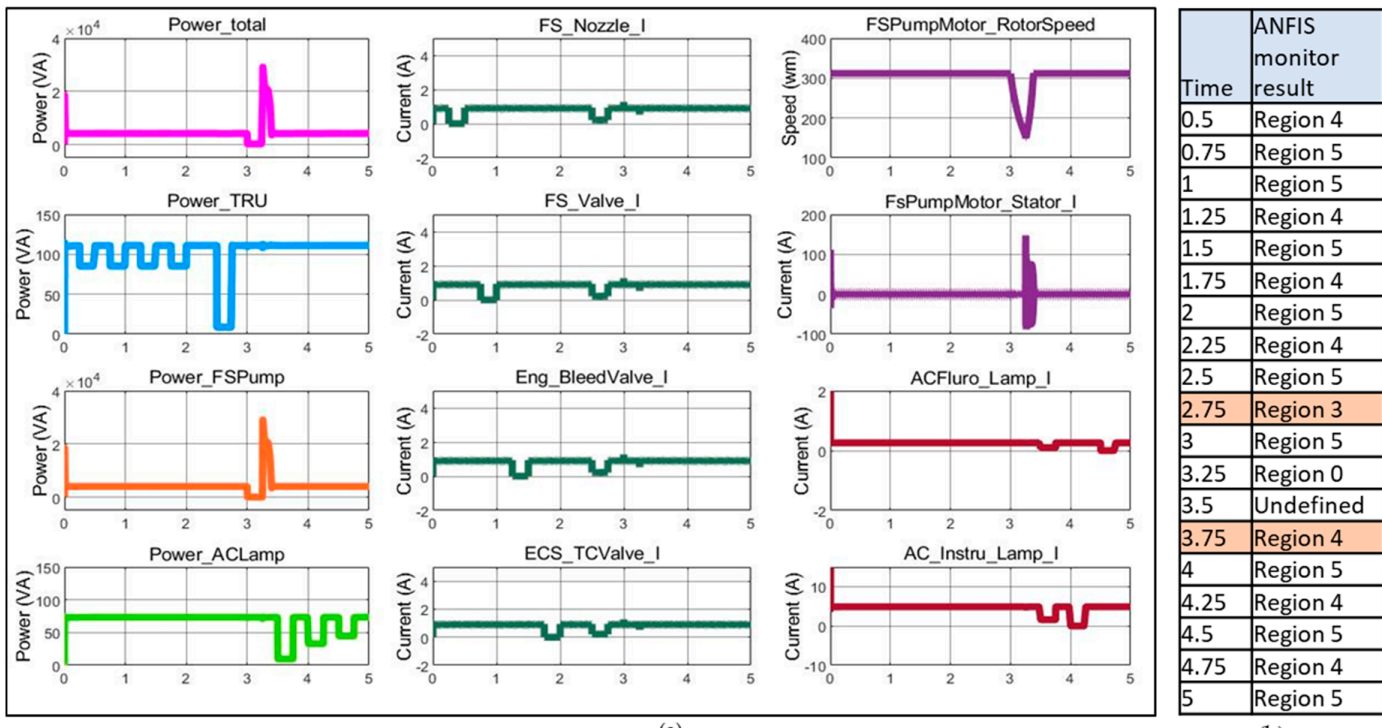

(a)

(b)

Figure 10. Faulty scenario using the crisp boundary approach. (a) EPS performance in faulty scenarios.

(b) The corresponding results generated by ANFIS monitor using Method 1 approach.

This inaccuracy in the detection of regions is due to the error in rounding up the values of ' $z$ ' while assigning the regions to each fault. The misclassification rate is high, at $67 \%$, as seen in Figure 11 , due to the inaccurate region assignments using crisp boundaries. Applying any additional approach like causal reasoning to this method will not be beneficial since the regions are not classified appropriately. In order to reduce the effect of this misclassification problem and to narrow down the fault to the concerned LRU, a fuzzy boundary approach is followed along with causal reasoning in Method 2.

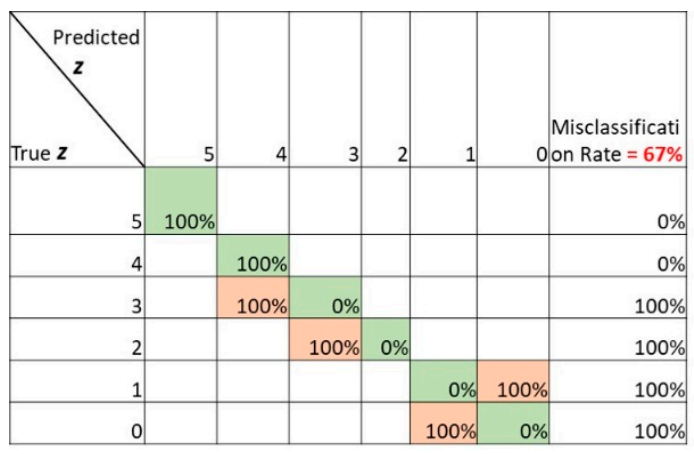

Correctly classified

Misclassified

Figure 11. Confusion matrix for the crisp boundary approach.

\subsection{Method 2: The Fuzzy Boundary Approach}

In method 2, the 'fuzzy boundary' concept is used since the crisp boundaries for processing the ANFIS output values ' $z$ ' did not work, as shown in Method 1 . Regions 5 to 0 are now representing multiple faults overlapping other regions (Figure 12) instead of representing only the 'defined' faults without any overlaps as in method 1. For example, from Figure 12a, it is seen that the fault F5 comes 
under both 'Region 2' and 'Region 3'. This method provides an accurate classification of faults into their regions, as shown in the confusion matrix in Figure 12b. In order to isolate the faults that propagate to other aircraft systems, the second method uses a hybrid combination of causal reasoning with ANFIS. Causal reasoning is a reasoning strategy that draws conclusions based on the cause and effect relationship of the concerned subjects [33]. In general, developing causal reasoning for a system such as EPS is a time-consuming and tedious task due to the large number of interactions between the EPS and other systems. However, with the combination of the ANFIS monitor similar to that in method 1 , their results can be used to narrow down the region of search for cause and effect relationships. The algorithm for implementing the method 2 approach is provided in Appendix A.

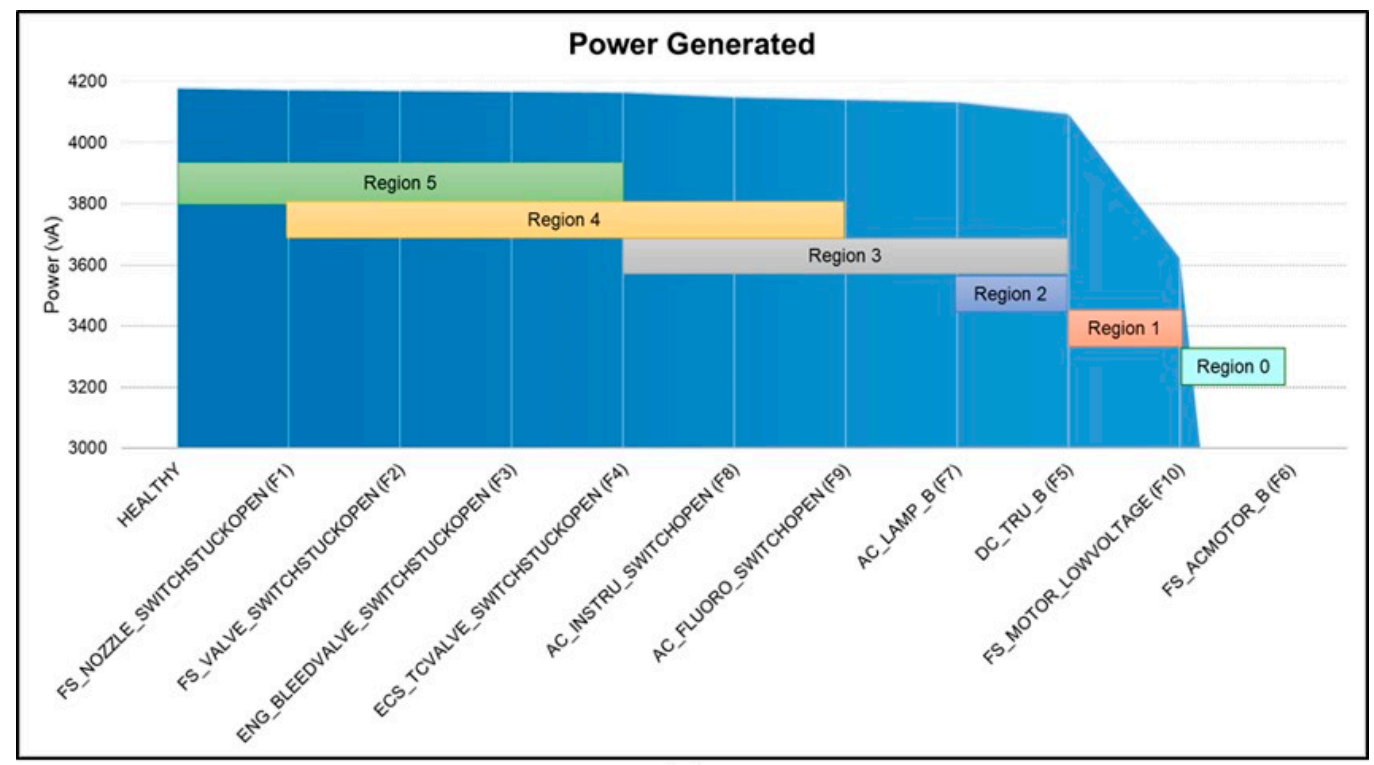

(a)

\begin{tabular}{|c|c|c|c|c|c|c|c|}
\hline True $\mathbf{Z}$ & 5 & 4 & 3 & 2 & 1 & & $\begin{array}{l}\text { Misclassification } \\
\text { Rate }=0 \%\end{array}$ \\
\hline 5 & $100 \%$ & & & & & & $0 \%$ \\
\hline 4 & & $100 \%$ & & & & & $0 \%$ \\
\hline 3 & & & $100 \%$ & & & & $0 \%$ \\
\hline 2 & & & & $100 \%$ & & & $0 \%$ \\
\hline 1 & & & & & $100 \%$ & & $0 \%$ \\
\hline 0 & & & & & & $100 \%$ & $0 \%$ \\
\hline
\end{tabular}

(b)

Figure 12. (a) Fuzzy boundaries representing healthy and faulty scenarios based on the power generated.

(b) Confusion matrix for method 2 ANFIS rank processing with fuzzy boundaries.

Using the ANFIS monitor, the 'effect' criteria for a particular region of faults is now narrowed down, which is followed by carrying out a certain number of tests to find out the exact 'cause' of the observed effect. This will be done by developing the diagnostic matrix that maps the required tests to be carried out for each region, and once the criteria of the tests are satisfied, the result will lead to the exact fault isolation. The diagnostic matrix for isolating the faults in the EPS is shown in Table 3. For every region identified by the ANFIS monitor, the voltages of the concerned LRUs are checked to isolate the faulty LRU. Carrying out every test in the table during every simulation run will consume a lot of time and memory, especially if the task is only to detect the presence of any fault. Thus, the 
application of the ANFIS monitor to detect the presence of a fault, followed by diagnosis using the diagnostic matrix, has the significant advantage of isolating the fault in the EPS in a shorter duration, with lesser memory.

Table 3. Diagnostic matrix for faults vs. tests.

\begin{tabular}{|c|c|c|c|c|c|c|c|c|c|c|c|}
\hline Region & Tests & F1 & F2 & F3 & F4 & F5 & F6 & F7 & F8 & F9 & F10 \\
\hline \multirow{2}{*}{5} & All DCValves_V $=$ V_Nominal & - & - & - & - & - & - & - & - & - & - \\
\hline & Any DCValve_V $<$ V_Nominal & $x$ & $x$ & $x$ & $x$ & - & - & - & - & - & - \\
\hline \multirow{2}{*}{4} & Any DCValve_V $<$ V_Nominal & $X$ & $X$ & $X$ & $X$ & - & - & - & - & - & - \\
\hline & Any ACLamp_V $<$ V_Nominal & - & - & - & - & - & - & - & $x$ & $x$ & - \\
\hline \multirow{3}{*}{3} & Any ACLamp_V $<$ V_Nominal & - & - & - & - & - & - & - & $x$ & $x$ & - \\
\hline & All ACLamps_V $<$ V_Nominal & - & - & - & - & - & - & $x$ & - & - & - \\
\hline & All DCValves_V $<$ V_Nominal & - & - & - & - & $x$ & - & - & - & - & - \\
\hline 2 & All DCValves_V $<$ V_Nominal & - & - & - & - & $X$ & - & - & - & - & - \\
\hline \multirow[t]{2}{*}{1} & $\begin{array}{c}\text { AC_Motor_Speed }<\text { Speed_Nominal \&\& } \\
\text { AC_Motor_Torque }> \\
\text { AC_Motor_Torque_min }\end{array}$ & - & - & - & - & - & - & - & - & - & $X$ \\
\hline & $\begin{array}{c}\text { AC_Motor_Speed }<\text { Speed_Nominal \&\& } \\
\text { AC_Motor_Torque }< \\
\text { AC_Motor_Torque_min }\end{array}$ & - & - & - & - & - & $x$ & - & - & - & - \\
\hline \multirow[t]{2}{*}{0} & $\begin{array}{c}\text { AC_Motor_Speed }<\text { Speed_Nominal } \& \& \\
\text { AC_Motor_Torque }> \\
\text { AC_Motor_Torque_min }\end{array}$ & - & - & - & - & - & - & - & - & - & $X$ \\
\hline & $\begin{array}{c}\text { AC_Motor_Speed }<\text { Speed_Nominal \&\& } \\
\text { AC_Motor_Torque }< \\
\text { AC_Motor_Torque_min }\end{array}$ & - & - & - & - & - & $X$ & - & - & - & - \\
\hline
\end{tabular}

An example of the end result, isolating a fault in the EPS, using the ANFIS monitor and the diagnostic matrix, is shown in Figure 13. The variable 'monitor_res' in Figure 13 shows the summarized output from the ANFIS monitor, which is then followed by the tests from the diagnostic matrix to isolate the F6 fault. Figure 14 shows the isolation of fault F5. Similarly, with the help of the diagnostic matrix, the tests are able to isolate the LRUs that are propagating faults to the other systems. While the ANFIS rank processing with the fuzzy boundaries classifies the regions of faults accurately, the overall classification accuracy of method 2 is $99.1 \%$. This is due to the slight overlaps between the healthy and DC Valves nominal voltages that are tested in Region 5. The tests carried out from the diagnostic matrix in Table 3 are able to isolate the faults accurately in the rest of the regions.

The diagnostic algorithm is tuned in to detect only the steady-state, single fault criteria, and hence, in any case of multiple or intermittent faults, the variable 'monitor_res' will give the result as 'Intermittent,' and the further diagnostic tests will be canceled. This can be seen in Figure 15a, where the fault F6 is injected between $\mathrm{t}=2.5 \mathrm{~s}$ to $\mathrm{t}=3.0 \mathrm{~s}$, the 'monitor_res' variable is 'Intermittent,' and there are no further diagnostic results. Similarly, in Figure 15b, multiple faults are injected for $0.5 \mathrm{~s}$ duration, (F5 between $t=2.5 \mathrm{~s}$ to $3.0 \mathrm{~s}$, and F8 between $\mathrm{t}=1.5 \mathrm{~s}$ to $\mathrm{t}=2.0 \mathrm{~s}$ ) and the end result is shown as 'Intermittent'. Thus, the hybrid combination of the ANFIS monitor with causal reasoning is capable of detecting and diagnosing both steady and unsteady state fault scenarios in the EPS, and it is also tunable as required. 

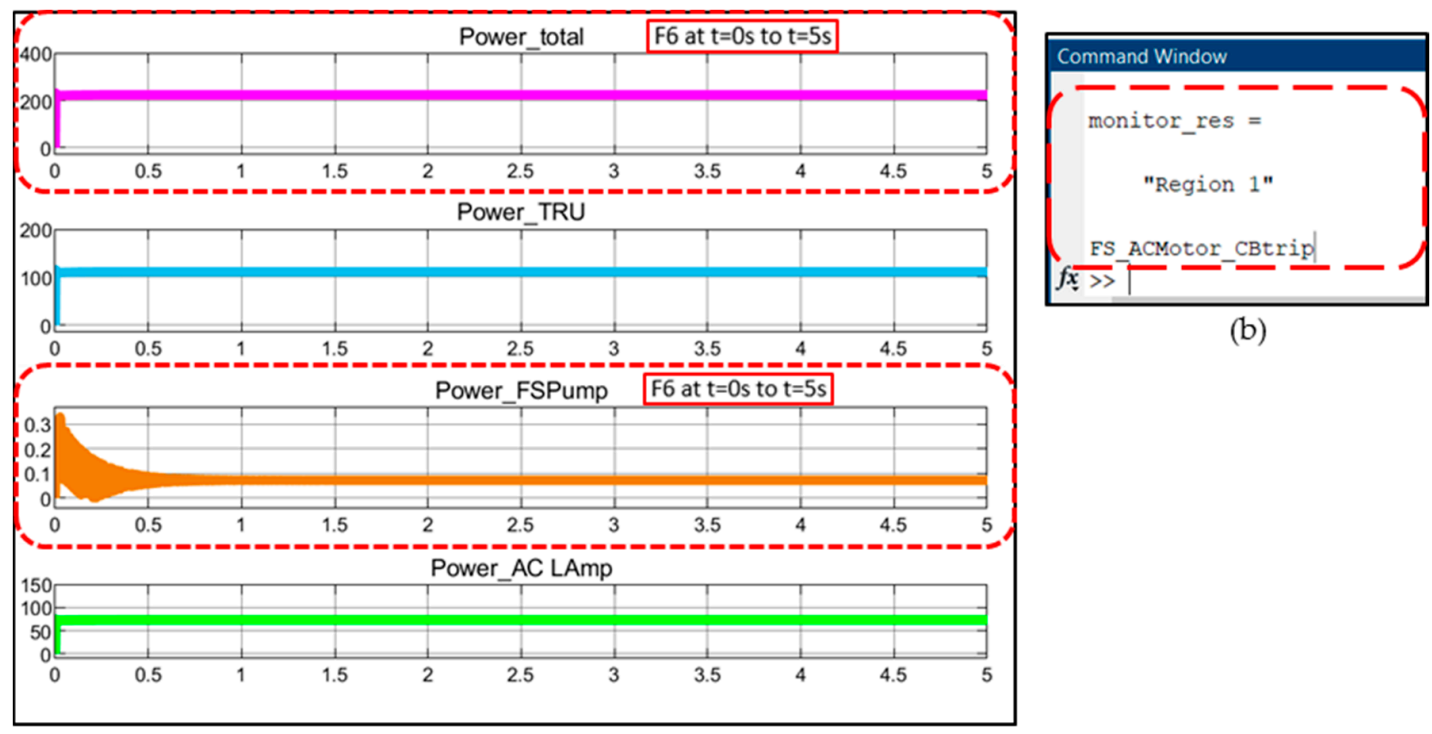

(b)

(a)

Figure 13. (a) Corresponding reaction in apparent power for ACMotor_Fault Injection (F6). (b) Method 2 results with the ANFIS monitor and causal reasoning.

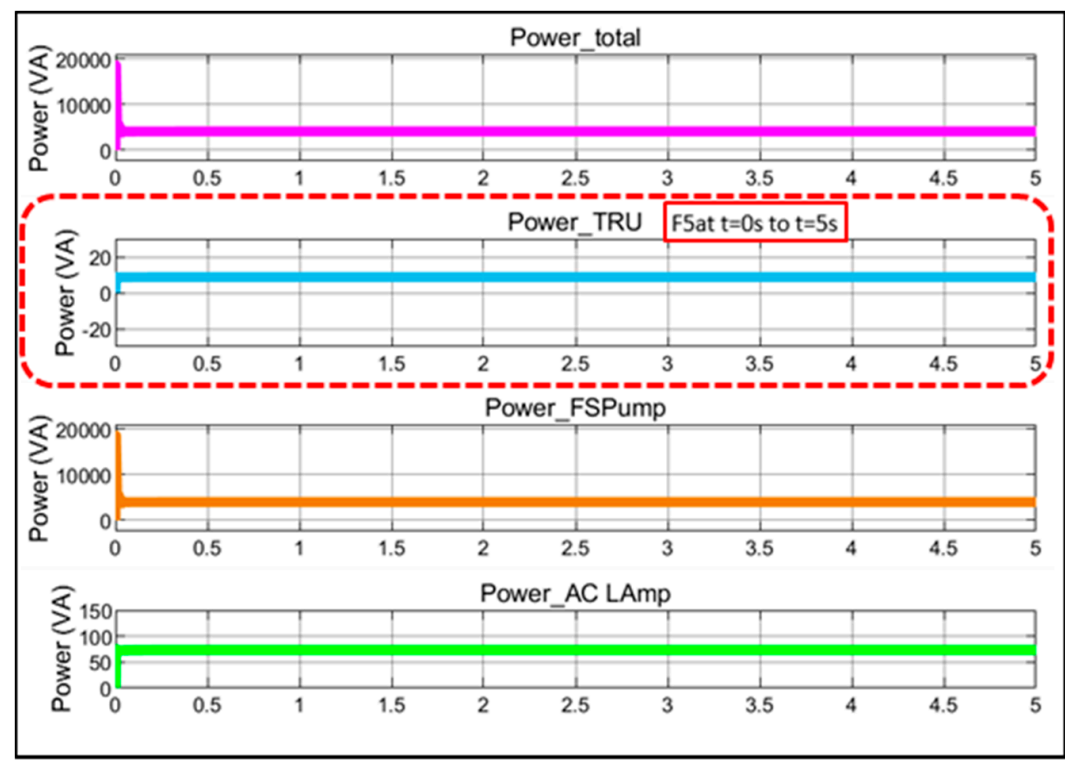

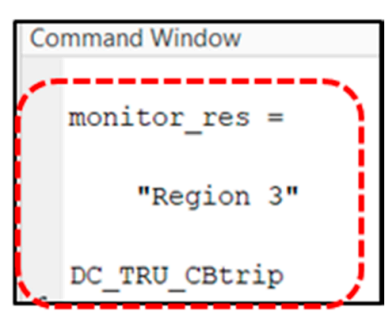

(b)

(a)

Figure 14. (a) Corresponding reaction in apparent power for DC TRU_CBtrip (F5) fault injection. (b) Method 2 results with the ANFIS monitor and causal reasoning. 

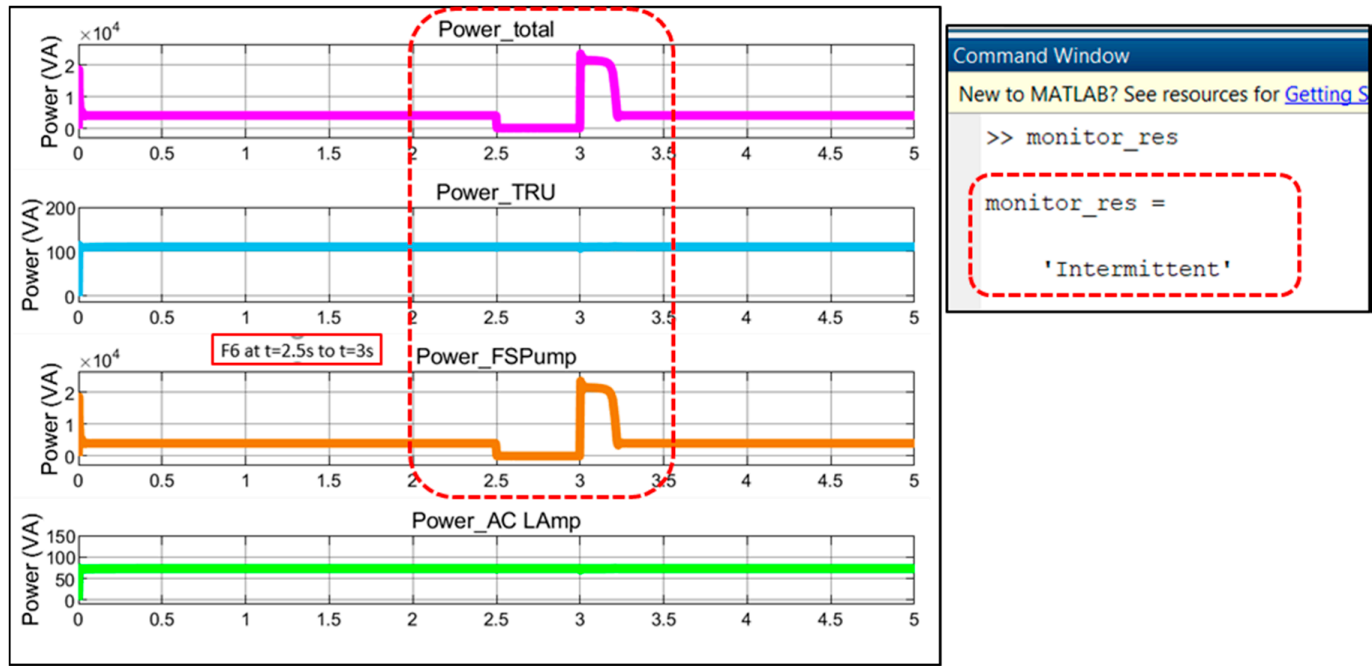

(a)
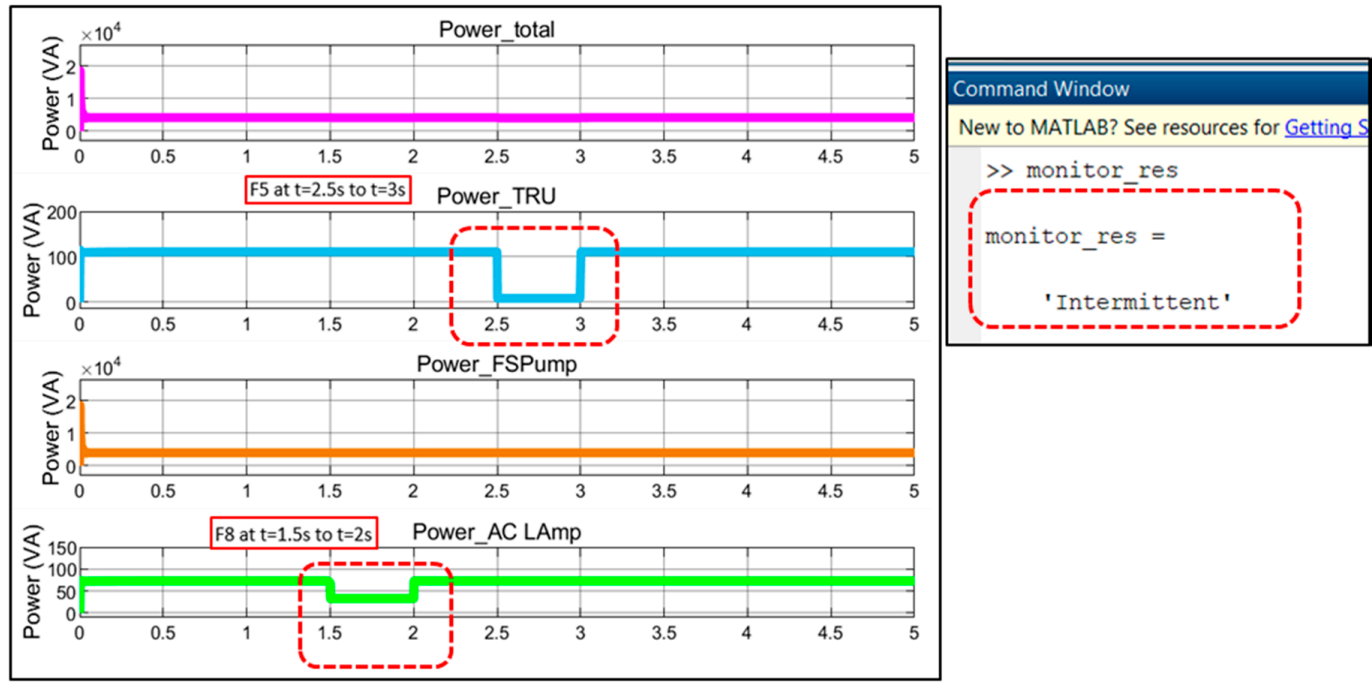

(b)

Figure 15. (a) Diagnostics for one intermittent fault (F6). (b) Diagnostics of multiple intermittent faults (F5, F8).

\section{Conclusions}

This paper discussed the importance of developing diagnostics for an Electrical Power System to isolate faults, including those that affect other systems like the engine, the fuel system, and the Environmental Control System of an aircraft. The development of an EPS digital twin, along with its simulation of healthy and faulty states, are presented. An ANFIS monitor is developed to detect the presence of faults in the EPS based on the power generated. Isolation of faults to particular LRUs is attempted by processing the ANFIS ranks in two methods: (i) a crisp boundary approach, and (ii) a fuzzy boundary approach. While the former provided a very high misclassification rate of $67 \%$, the second method was able to classify the faults to their regions accurately. This fuzzy boundary method is combined with causal reasoning by developing tests for every region through a diagnostic matrix, through which the faults that propagate to LRUs of other aircraft systems are isolated. The developed diagnostic algorithm with ANFIS is tunable to monitor the power generated at desired time windows and is also capable of identifying the intermittency during the simulation run.

With these results from EPS diagnostics, it is possible to pinpoint the location and time where a fault has occurred, thus reducing the time taken to troubleshoot the root cause of faults effectively. This method will help in preventing ambiguous scenarios like the aircraft incidents presented in 
Section 1 , where the effect is significantly observed in the interacting system rather than the system of origin. As the combination of the ANFIS monitor with causal reasoning does not take much time to isolate the faults during the simulation run, this diagnostic method could be tried in both ground systems as well as onboard highly electrified aircraft for rapid diagnosis in the case of real-time fault scenarios. As this diagnostic method is not heavy on computation requirements, it is also helpful for monitoring the health of the aircraft at the vehicle level, considering the interaction between its multiple systems. A framework of digital twins of multiple interacting systems like the EPS, the engine, the ECS, and the fuel system, along with their system-level diagnostics isolating the interacting faults, would help in monitoring the overall health of the aircraft [5].

Author Contributions: Conceptualization, C.M.E., and I.K.J.; Methodology, C.M.E.; Software, C.M.E.; Validation, C.M.E.; Formal analysis, C.M.E.; Investigation, C.M.E.; Resources, I.K.J.; Data curation, C.M.E.; Writing-original draft preparation, C.M.E.; Writing-review and editing, C.M.E. and I.K.J.; Visualization, C.E.; Supervision, I.K.J.; Project administration, I.K.J.; Funding acquisition, I.K.J. All authors have read and agreed to the published version of the manuscript.

Funding: This work has been funded by The Boeing Company as part of their collaboration with Cranfield University's IVHM Centre. The authors would like to thank Boeing for their support of this project.

Conflicts of Interest: The authors declare no conflict of interest. The funders had no role in the design of the study; in the collection, analyses, or interpretation of data; in the writing of the manuscript, or in the decision to publish the results.

\section{Appendix A}

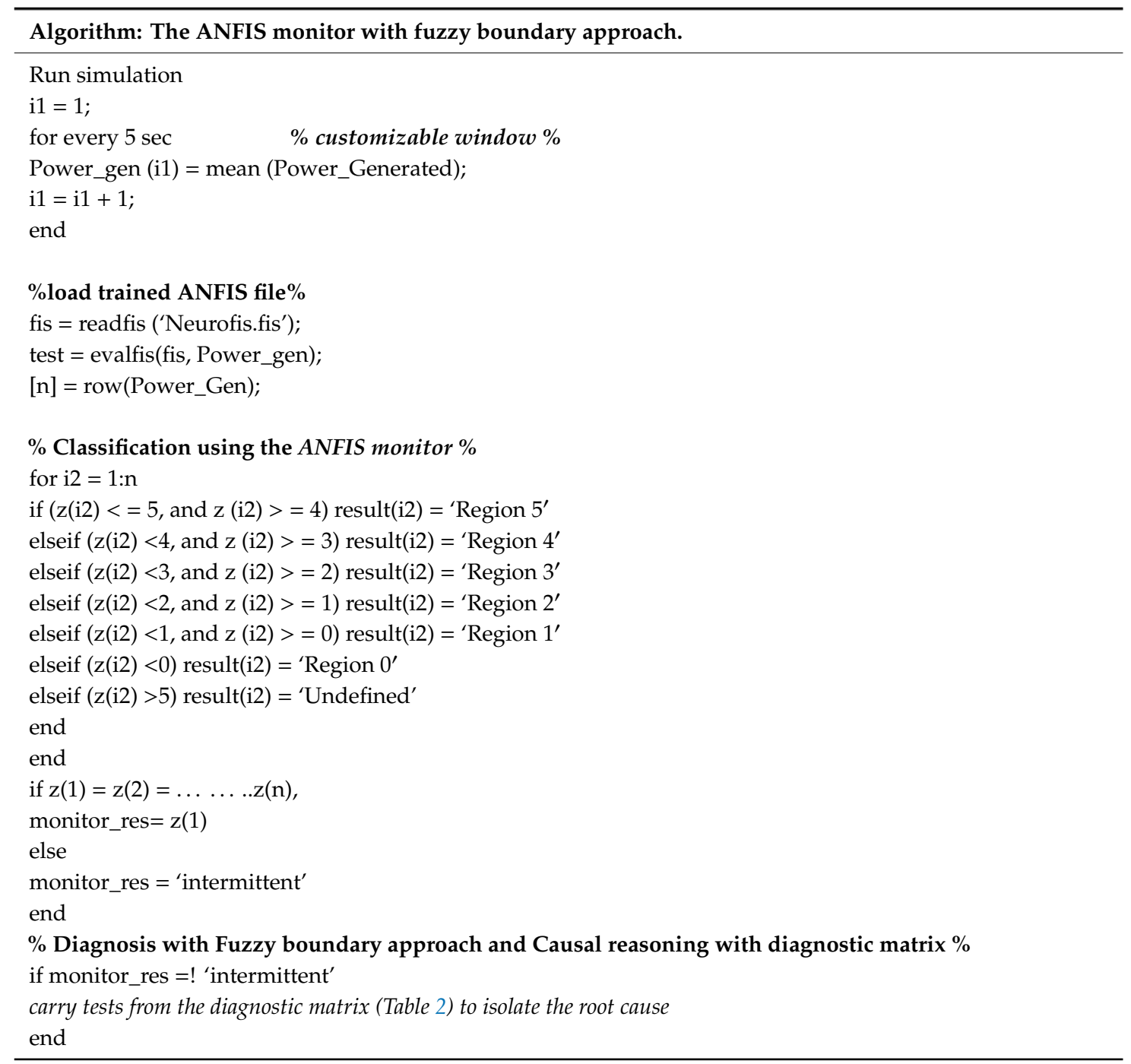




\section{References}

1. Zumberge, J.; Wolff, J.; McCarthy, K.; O'Connell, T.; Walters, E.; Russell, G.; Lucas, C. Integrated Aircraft Electrical Power System Modeling and Simulation Analysis. SAE Techn. Paper Ser. 2010. [CrossRef]

2. Rosero, J.; Ortega, J.; Aldabas, E.; Romeral, L. Moving towards a more electric aircraft. IEEE Aerosp. Electron. Syst. Mag. 2007, 22, 3-9. [CrossRef]

3. Air Accidents Investigation Branch. AAIB Bulletin: 4/2014 9M-MPL EW/C2012/08/04. Available online: https://www.gov.uk/aaib-reports/boeing-747-4h6-9m-mpl-17-august-2012 (accessed on 1 March 2020).

4. Air Accidents Investigation Branch. Aircraft Accident Report No: 4/2009. Available online: https://assets.publishing.service.gov.uk/media/552659a7e5274a141800000d/Summary_AAR_4-2009_ Airbus_A319-111_G-EZAC_09-09.pdf (accessed on 1 March 2020).

5. Ezhilarasu, C.M.; Skaf, Z.; Jennions, I.K. Progress towards a Framework for Aerospace Vehicle Reasoning (FAVER). In Proceedings of the Annual Conference of the PHM Society, Scottsdale, AZ, USA, 21-22 September 2019; pp. 1-9.

6. Sweet, A. Testing HyDE on ADAPT. NASA STI Technical Memorandum; 2008. Available online: https: //ntrs.nasa.gov/archive/nasa/casi.ntrs.nasa.gov/20080017209.pdf (accessed on 5 March 2020).

7. Knox, W.B.; Mengshoel, O.J. Diagnosis and Reconfiguration using Bayesian Networks: An Electrical Power System Case Study. In Proceedings of the IJCAI-09 Workshop on Self- $\backslash$ star and Autonomous Systems (SAS): Reasoning and Integration Challenges, Paris, France, 2-5 May 2009; pp. 67-74.

8. Ricks, B.W.; Mengshoel, O.J. Methods for Probabilistic Fault Iagnosis: An Electrical Power System Case Study. Annual Conference of the Prognostics and Health Management Society, PHM 2009; NASA: Washington, DC, USA, 2009; pp. 1-12.

9. McIntire, M.G.; Keshavarzi, E.; Tumer, I.Y.; Hoyle, C. Functional Models with Inherent Behavior: Towards a Framework for Safety Analysis Early in the Design of Complex Systems. Adv. Aerosp. Technol. 2016, 1-8. [CrossRef]

10. Mengshoel, O.J.; Darwiche, A.; Cascio, K.; Chavira, M.; Poll, S.; Uckun, N.S. Diagnosing Faults in Electrical Power Systems of Spacecraft and Aircraft. Artif. Intell. 2008, 650, 1699-1705.

11. Cao, Y.; Liu, G.; Liu, Z. Condition Based Maintenance for Aircraft Electrical Systems. SAE Tech. Paper Ser. 2009. [CrossRef]

12. Batzel, T.D.; Swanson, D.C. Prognostic Health Management of Aircraft Power Generators. IEEE Trans. Aerosp. Electron. Syst. 2009, 45, 473-482. [CrossRef]

13. Faiz, J.; Ghorbanian, V.; Joksimovic, G. Fault Diagnosis of Induction Motors. In Proceedings of the 1st Annual International Interdisciplinary Conference, Azores, Portugal, 24-26 April 2017.

14. Sekar, B.D.; Dong, M.C. Bayesian fuzzy inference nets online fault diagnosis of induction motor. In Proceedings of the 7th International Conference on Information, ICICS 2009-Conference, Communications and Signal Processing, Aizuwakamatsu, Japan, 15-17 June 2009.

15. Seok, J.; Kolmanovsky, I.; Girard, A. Integrated/coordinated control of aircraft gas turbine engine and electrical power system: Towards large electrical load handling. In Proceedings of the 2016 IEEE 55th Conference on Decision and Control (CDC), Las Vegas, NV, USA, 12-14 December 2016; pp. 3183-3189.

16. Shi, X.; Qu, J.; Wu, H.; Cai, J.; Yang, Z. Modelling and simulation of the logical structure of aircraft power distribution systems. Int. J. Simul. Syst. Sci. Technol. 2016, 17, 37.1-37.9.

17. Boeing. THE BOEING 737 TECHNICAL SITE. Available online: http://www.b737.org.uk/electrics.htm (accessed on 3 March 2020).

18. Madonna, V.; Member, S.; Giangrande, P.; Galea, M. Electrical Power Generation in Aircraft: Review, Challenges and Opportunities. Res. Gate 2018. [CrossRef]

19. Olivier Tremblay L-AD. Aircraft Electrical Power Generation and Distribution. MathWorks. Available online: https://www.mathworks.com/help/physmod/sps/examples/aircraft-electrical-power-generation-anddistribution.html (accessed on 23 February 2020).

20. Steve, M. Aircraft Power Network in Simscape Electrical. MathWorks, 2018. Available online: https://www. mathworks.com/matlabcentral/fileexchange/44124-aircraft-power-network-in-simscape-electrical/ (accessed on 23 February 2020).

21. Mushiri, T.; Mbohwa, C. Research on the use of matlab in the modeling of 3-phase power systems. In Proceedings of the World Congress on Engineering, London, UK, 1-3 July 2015; pp. 363-369. 
22. MathWorks. Asynchronous Machine. Available online: https://www.mathworks.com/help/physmod/sps/ powersys/ref/asynchronousmachine.html (accessed on 23 February 2020).

23. MathWorks. Simplified Synchronous Machine. Available online: https://www.mathworks.com/help/ physmod/sps/powersys/ref/simplifiedsynchronousmachine.html (accessed on 23 February 2020).

24. MathWorks. Excitation Systems. Available online: https://www.mathworks.com/help/physmod/sps/ powersys/ref/excitationsystem.html (accessed on 23 February 2020).

25. OECO. Transformer Rectifiers. Available online: https://www.oeco.com/wp-content/uploads/2015/07/ transformer-rectifier-units.pdf (accessed on 5 March 2020).

26. Eaton. Fuel Boost Pump Type 20004 and Canister Type 20005. Available online: https://www.eaton.com/ Eaton/ProductsServices/Aerospace/Fuel/FuelBoostPumps/index.htm (accessed on 5 March 2020).

27. Aerodynamix Inc. Aircraft Instrument Panel Lighting. Available online: https://aerodynamix.com/aircraftinstrument-panel-lighting/ (accessed on 3 March 2020).

28. Valcor Aerospace. 2-Way Normally Open or Normally Closed Shut-Off Solenoid Valve. 2015. Available online: https://www.valcor.com/v4700-2-way-shut-solenoid-valve/ (accessed on 5 March 2020).

29. Diyoke, G.C.; Okeke, C.; Aniagwu, U. Different Methods of Speed Control of Three-Phase Asynchronous Motor. Am. J. Electr. Electron. Eng. 2016, 4, 62-68.

30. Jang, J.S.R. ANFIS: Adaptive-Network-Based Fuzzy Inference System. IEEE Trans. Syst. Man Cybern. 1993, 23, 665-685. [CrossRef]

31. MathWorks. Fuzzy Logic Toolbox. Available online: https://www.mathworks.com/help/fuzzy/ (accessed on 23 February 2020).

32. Bystrov, D.; Westin, J. Neuro-Fuzzy Logic Systems. MathWorks. 2015, pp. 69-76. Available online: https://users.du.se/ \{\}\}we/fuzzy/NFL/F10.PDF (accessed on 10 February 2020).

33. Ezhilarasu, C.M.; Skaf, Z.; Jennions, I. The application of reasoning to aerospace Integrated Vehicle Health Management (IVHM): Challenges and opportunities. Prog. Aerosp. Sci. 2019, 105, 60-73. [CrossRef]

(C) 2020 by the authors. Licensee MDPI, Basel, Switzerland. This article is an open access article distributed under the terms and conditions of the Creative Commons Attribution (CC BY) license (http://creativecommons.org/licenses/by/4.0/). 